\title{
Effects of Post-Injection Characteristics on the Combustion, Emission, and Performance in a Diesel-Syngas Reactivity Controlled Compression Ignition Engine
}

\author{
M.J. Noroozi* and M. Seddiq \\ Department of Mechanical Engineering, Ayatollah Boroujerdi University, PO Box: 69199-69411, Borujerd, Iran
}

ABSTRACT - This paper presents a numerical investigation of the separate effects of postinjection characteristics in a heavy-duty turbocharged direct injection diesel engine under pure diesel combustion (PDC) and diesel-syngas combustion (DSC) operating conditions. Converge CFD code was used coupled with a detailed n-heptane/toluene/PAH chemical kinetic mechanism (consists of 71 species and 360 reactions) for diesel-syngas dual-fuel combustion simulation. A total of 36 strategies based on the post-injection characteristics (post-injection timing, fuel quantity, spraying pressure, and main-post dwell time) on the combustion characteristics, exhaust gas emissions, and engine performance under PDC and DSC conditions were investigated. Numerical achievements revealed that $40 \%$ substitution of diesel fuel with syngas significantly decreased particulate matter emission and enhanced the indicated thermal efficiency (ITE), compared to the baseline PDC case. However, carbon monoxide noticeably increased. In addition, retarding the post-injection timing prolonged the combustion duration and also reduced the nitrogen oxides emissions and ITE. By increasing the post-injection quantity up to $15 \%$, the combustion process deteriorated, and carbon-based emissions such as particulate matter, carbon monoxide, and unburnt hydro-carbon in the exhaust gases increased under PDC and DSC conditions. Furthermore, increasing post-injection pressure (PIP) from 1000 to 1450 bar under both PDC and DSC conditions led to higher flame temperature, and as a result, the heat release rate peak point and temperature peak point for the second combustion event increased. However, at a PIP of 1600 bar, the ITE deteriorated under PDC and DSC operating cases.
ARTICLE HISTORY

Received: $16^{\text {th }}$ April 2020

Revised: $17^{\text {th }}$ Aug 2021

Accepted: $7^{\text {th }}$ Sept 2021

KEYWORDS

Combustion characteristics; Syngas;

Diesel;

Post-injection;

Emissions

\section{NOMENCLATURE}

$\begin{array}{llll}\text { AFR } & \text { air-fuel ratio } & \text { ITE } & \text { indicated thermal efficiency } \\ \text { AMR } & \text { adaptive mesh refinement } & \text { IVC } & \text { intake valve close } \\ \text { BTDC } & \text { before top dead center } & \text { MIT } & \text { main-injection timing } \\ \text { CA } & \text { crank angle } & \text { NOx } & \text { nitrogen oxides } \\ \text { CFD } & \text { computational fluid dynamic } & \text { NTC } & \text { no-time-counter } \\ \text { CI } & \text { compression-ignition } & \text { PAH } & \text { poly aromatic hydrocarbon } \\ \text { CO } & \text { carbon monoxide } & \text { PDC } & \text { pure diesel combustion } \\ \mathrm{CO}_{2} & \text { carbon di-oxides } & \text { PIP } & \text { post-injection pressure } \\ \text { DI } & \text { direct injection } & \text { PIQ } & \text { post-injection quantity } \\ \text { DOI } & \text { duration of injection } & \text { PIT } & \text { post-injection timing } \\ \text { DSC } & \text { diesel syngas combustion } & \text { PM } & \text { particulate matter } \\ \text { EGR } & \text { exhaust gas recirculation } & \text { RNG } & \text { re-normalised group } \\ \text { EVO } & \text { exhaust valve opening } & \text { RPM } & \text { revolution per minute } \\ \text { HCE } & \text { hydrogen combustion efficiency } & \text { SOI } & \text { start of injection } \\ \text { HRR } & \text { heat release rate } & \text { TDC } & \text { top dead center } \\ \text { HRRPP } & \text { heat release rate peak point } & \text { TDI } & \text { turbocharged direct injection } \\ \text { HSDI } & \text { high speed direct injection } & \text { TPP } & \text { temperature peak point } \\ \text { ID } & \text { ignition delay } & \text { UHC } & \text { unburnt hydro-carbon } \\ \text { IT } & \text { injection timing } & & \end{array}$

\section{INTRODUCTION}

The considerable increase in the number of vehicles simultaneous with population growth caused a significant increase in fossil fuels consumption as well as greenhouse gases. For this reason, demands for compression ignition engines due to lower fuel consumption and $\mathrm{CO} / \mathrm{CO}_{2}$ emissions compared to gas and gasoline engines has been increased [1]. However, 
diesel engines produce substantial amounts of NOx and PM emissions due to the formation of regions with high temperatures as well as high equivalence ratios during combustion [2]. Hence, diesel engines have many problems regarding exhaust gas emissions that violate environmental laws.

Over the past several years, numerous computational and experimental studies have been conducted to reduce the harmful pollutants (e.g., NOx and PM) emitting by diesel engines [3-7]. Recent experimental and numerical investigations show that many researchers still focus on using post-injection of diesel fuel to meet emission regulations in single and dual-fuel engines. In their paper, Liu and Song [8] conducted an experimental study on the effects of using post-injection on emissions formation in an HSDI compression ignition engine. They have reported that by retarding the post-injection timing, the amounts of both UHC and CO emissions increased simultaneously. However, NOx noticeably decreased, which was attributed to a lower in-cylinder temperature during the expansion stroke, leading to an inefficient late air-fuel mixture formation. Also, they have shown that by increasing the time interval between fuel injection events (advancing main-injection timing), PM emission decreased. In another research paper, Li et al. [9] provided a discussion of the effects of post-injection characteristics such as main-post time intervals and post-injection rate on exhaust gas emissions in a light-duty DI diesel engine. According to their obtained results, more extended main-post injection interval or increasing post-injection rate leads to more UHC and CO but lower NOx emissions. Also, for both short and long main-post injection intervals, the amount of PM emission extensively increased at $12 \%$ and $20 \%$ post-injection rates. Wu et al. [10] experimentally conducted a similar study on the influence of post-injection strategies on the combustion process and emissions formation in a diesel/methanol dual-fuel compression ignition engine. Their results revealed that simultaneous applying of high methanol/diesel ratio and post-injection reduce the amounts of both NOx and PM emissions. In addition to that, increasing post-injection quantity has led to a reduction of NOx and PM.

Furthermore, researchers observed that low post-injection quantity has slight effects on in-cylinder heat release rate and mean pressure. In other research, Wu et al. [11] conducted an experimental study on the impacts of applying diesel post-injection in CI engine. They observed that post-injection timing had a critical influence on PM formation. Moreover, they reported that by retarding the post-injection timing, UHC emissions increased and totally, NOx emission reduced by nearly $26.7 \%$ compared to single-injection case. In addition, in terms of engine performance, Pan et al. [12] indicated that thermal efficiency reached $36.9 \%$ under PDC conditions when the post-injection ratio was low (25\%). One of the practical approaches regarding emissions reduction in diesel engines is reactivity controlled combustion strategy. This approach is based on low-temperature combustion and leads to the simultaneous decrement of both PM and NOx emissions. However, lower exhaust gas temperature leads to higher UHC and CO emissions [13]. For this reason, the use of gaseous fuels such as hydrogen and methane gas, due to low or none carbon content, which can cause less carbon-based emission formation attracted lots of attention. Yousefi et al. [14] conducted an experimental/numerical study on the effects of diesel injection timing in a natural gas/diesel CI engine. Their findings revealed that by advancing diesel injection timing, overall unburnt methane decreased, thermal efficiency improved, and NOx emissions increased. However, unburnt methane near the incylinder crevices and walls slightly increased. In their study, Hernandez et al. [15] have investigated the impacts of separate addition of $\mathrm{H}_{2}$ and $\mathrm{CO}$ gases on the emissions formation in a $2.0 \mathrm{~L}$ single-cylinder TDI diesel engine. Their results reveal that by the addition of $\mathrm{H}_{2}$ into the combustion chamber, due to thermal and chemical characteristics of hydrogen gas, PM and UHC noticeably decreased, but NOx slightly increased. However, they reported that using CO as a gaseous fuel additive resulted in more $\mathrm{CO}$ and $\mathrm{UHC}$ emissions in the exhaust gases.

In another experimental research, Talibi et al. [16] explored the effects of $\mathrm{H}_{2}$ addition on exhaust gas emissions in an HSDI diesel engine. Based on their results, using hydrogen gas led to a reduction of both PM and CO emissions and increment of HRR peak point simultaneously. Also, at low load operating conditions, $\mathrm{H}_{2}$ addition reduced NOx emissions. In another research work, Ebrahimi and Jazayeri [17] indicated that under landfill gas/diesel oil operating conditions, addition and increasing hydrogen gas led to lower both NOx and CO emissions simultaneously. Moreover, they noticed that increment of $\mathrm{H}_{2}$ gas rate to the combustion chamber enhanced the air-fuel mixture oxidation, shortened the combustion duration, but prolonged the ID period. In another similar study by Zareei et al. [18], impacts of $\mathrm{H}_{2}$ induction to the engine cylinder at natural gas/diesel operating conditions were investigated. Their numerical achievements indicated that increasing hydrogen gas into the combustion chamber increased engine performance. However, NOx level increased, but carbon-based emissions such as UHC and PM emissions reduced.

The use of syngas (gaseous fuel composed of $\mathrm{CO}$ and $\mathrm{H}_{2}$ gases) as a low reactivity fuel has several advantages like no need for EGR systems, reduce the secondary fueling system costs, and increase of fuel conversion efficiency of the system by recovery of energy loss through exhaust gases over the fuels such as natural gas and gasoline-like fuels [19, 20]. Since the syngas itself is composed of hydrogen gas, emissions such as PM and UHC can be considerably decreased due to lean mixture formation (high AFR) and high HRR that leads to an increase of flame temperature [21]. However, due to the high flame speed of $\mathrm{H}_{2}$ gas and the existence of $\mathrm{CO}$ in the syngas fuel, NOx and $\mathrm{CO}$ emissions can vastly increase in the exhaust gases [22]. For this reason, the authors of this research decided to investigate the simultaneous impacts of applying syngas fuel and post-injection characteristics such as injection timing, fuel ratio, and pressure on the combustion characteristics, emission formation, and performance in a heavy-duty off-road RCCI engine.

\section{Model Setup}

This numerical study and all of its relative calculations were conducted using the Converge CFD code [23]. Also, Converge CFD tools were used for generating the computational grid. Because of using a seven-hole injector and symmetrical shape of the combustion chamber, all computations were conducted on 51.42 degrees segment. Base grid size set to $1 \mathrm{~mm}$ in $\mathrm{x}, \mathrm{y}$, and $\mathrm{z}$ directions. Four levels of fixed embedding were applied to the boundaries, such as cylinder 
head, piston, and spray cone area. AMR with a scale of 2 was set for resolving temperature and velocity in high turbulent regions (e.g., flame region). In addition, sub-grid criteria for temperature and velocity was set at $5 \mathrm{~K}$ and $2 \mathrm{~m} / \mathrm{s}$, respectively. Based on the employed settings, the smallest grid size used in the calculations is $0.25 \mathrm{~mm}$, which is suitable for solving flame front and diesel spray. Figure 1 shows the computational grid at the TDC point.

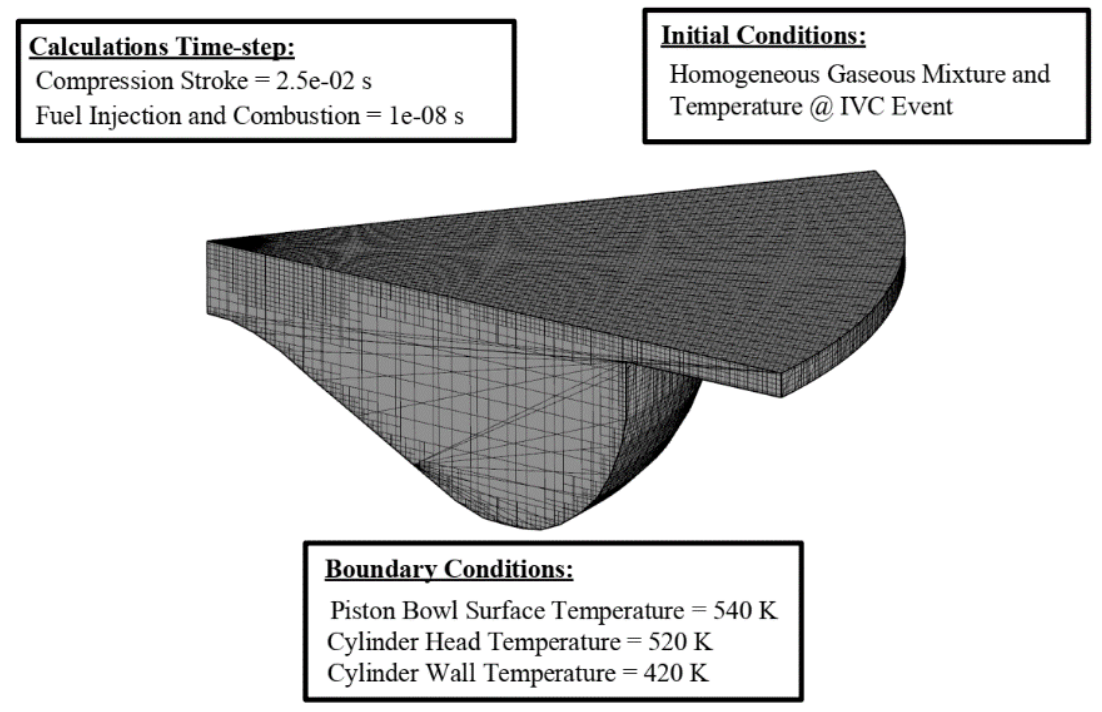

Figure 1. The computational grid at TDC point.

For simulating the diesel-syngas dual-fuel combustion process, the SAGE model [24] was used coupled with a detailed n-heptane/toluene/PAH chemical kinetic mechanism which consists of 71 species and 360 reactions [25]. For heavy reactivity DI fuel, the physical properties of tetradecane $\left(\mathrm{C}_{14} \mathrm{H}_{30}\right)$ and chemical specifications of heptane $\left(\mathrm{n}-\mathrm{C}_{7} \mathrm{H}_{16}\right)$ were considered [23]. The multi-zone chemistry model [26] was used coupled with the SAGE combustion model to reduce total computation time by considering cells with the same thermodynamic properties into one region. Kelvin-Helmholtz (KH) and Rayleigh-Taylor (RT) models [27] were applied for computing the primary and secondary atomisation of sprayed fuel parcels. For taking parcels collision into account, the NTC model method [28] of Schmidt and Rutland was used, coupled with Naber and Reitz spray-wall interaction model [29]. In addition to that, for modelling the fuel parcels evaporation process, the Frossling correlation method of Amsden et al. [30] was applied. Moreover, the RNG K-epsilon model developed by Yakhot et al. [31] was used to simulate the turbulence flow inside the combustion chamber.

\section{Model Validation}

The engine used for this numerical research is a single-cylinder heavy-duty diesel engine made by Caterpillar Company. Table 1 presents the specifications of the engine [32]. The test engine is equipped with a common rail direct injection system that its specifications can be found in Table 2 [32].

Table 1. Engine specifications [32].

\begin{tabular}{lc}
\hline Engine Name & Caterpillar 3401 \\
\hline Type of Aspiration & Turbocharged \\
Bore x Stroke (mm) & $137.2 \times 165.1$ \\
Engine displacement (L) & 2.44 \\
Compression ratio (-) & $16.1: 1$ \\
Connecting rod length (mm) & 261.6 \\
Number of valves & 4 \\
IVC (CA BTDC) & 143 \\
EVO (CA BTDC) & -130 \\
Swirl ratio (-) & 0.7 \\
\hline
\end{tabular}

Table 2. Fuel injection system specifications [32].

\begin{tabular}{lc}
\hline Injector holder & Bosch CRIN-2 \\
\hline Number of orifices & 7 \\
Spray angle (degree) & 148 \\
Orifice diameter (mm) & 0.141 \\
Injection pressure (bar) & 1000 \\
Nominal hydraulic flow (cc per 30 s @ 100 bar) & 440 \\
\hline
\end{tabular}

This numerical study is conducted at PDC and DSC conditions in which full descriptions of engine operating modes are presented in Table 3 [32]. All numerical achievements from the simulation of the engine baseline operating conditions 
(PDC and DSC) such as in-cylinder mean pressure, HRR and exhaust gas emissions were compared to Chuahy and Kokjohn experimental data [32]. Also, the thermochemical specifications of consumed fuels are listed in Table 4.

Table 3. Experimental engine operating conditions [32].

\begin{tabular}{lcc}
\hline Combustion Mode & PDC & DSC \\
\hline Intake air pressure (bar) & \multicolumn{2}{c}{1.7} \\
Intake air temperature (K) & \multicolumn{2}{c}{350} \\
EGR rate (\%) & \multicolumn{2}{c}{4 (residual) } \\
Fuel injection timing (CA BTDC) & \multicolumn{2}{c}{10} \\
Engine speed (RPM) & \multicolumn{2}{c}{1300} \\
Fuel injection pressure (bar) & 1000 \\
Diesel mass (mg) & 35 & 72 \\
AFR (-) & \multicolumn{2}{c}{54} \\
Total energy per cycle (J) & $0 / 100$ & $40 / 60$ \\
Syngas/diesel ratio (Energy fraction \%) & - & $50 / 50$ \\
$\mathrm{H}_{2} /$ CO volumetric ratio of syngas (\%) & \multicolumn{2}{c}{} \\
\hline
\end{tabular}

Table 4. Fuels specifications [32, 33].

\begin{tabular}{lccc}
\hline Fuel & Chevron Diesel & Hydrogen & Carbon Monoxide \\
\hline Chemical Formula & $\mathrm{CH}_{1.825}$ & $\mathrm{H}_{2}$ & $\mathrm{CO}$ \\
$\mathrm{H} / \mathrm{C}$ ratio & 1.825 & 2 & 0 \\
O/C ratio & 0 & 0 & 1 \\
Cetane number & 53 & - & - \\
Octane number & - & 140 & 106 \\
Density (g/L) & 830.9 & 0.09 & 1.14 \\
Minimum ignition energy (For $\varphi=1)(\mathrm{MJ})$ & 20 & 0.02 & - \\
Flame velocity (For $\varphi=1)$ & 0.3 & 1.85 & - \\
Lower heating value $(\mathrm{MJ} / \mathrm{Kg})$ & 43.193 & 119.96 & 10.11 \\
\hline
\end{tabular}

Figure 2 reports the comparison between the measured and predicted in-cylinder mean pressure and HRR at PDC and DSC operating conditions [32]. According to Figure 2, the relative errors in the in-cylinder peak pressure under PDC and DSC conditions are 0.7 and $2.5 \%$, respectively. Thus, it can be concluded that under both engine operating conditions, in-cylinder mean pressure and rate of heat release trends were simulated with an acceptable accuracy compared to experimental results. The comparison between the experimental and numerical results for exhaust gas emissions at both engine operating modes can be found in Table 5. As can be seen from this table, there is a reasonable agreement between numerical and experimental results, which can be concluded that the emissions formation was modelled with acceptable accuracy.

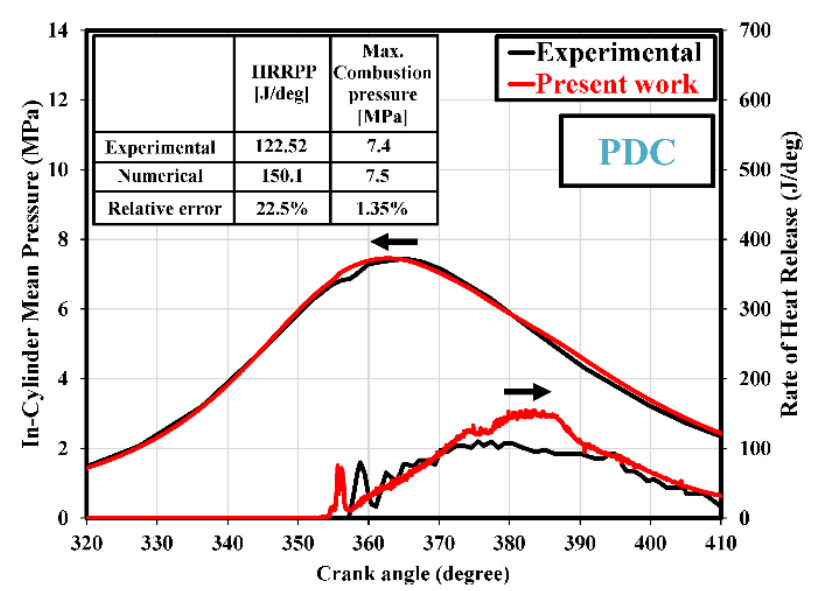

(a) PDC operating conditions

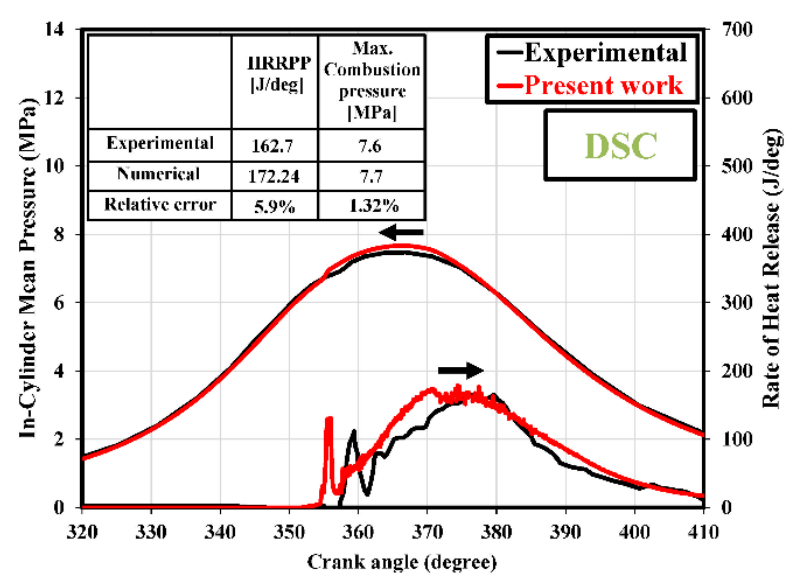

(b) DSC operating conditions

Figure 2. Comparison between numerical and experimental heat release rate and in-cylinder mean pressure trends for (a) PDC and (b) DSC operating conditions [32]

Table 5. Numerical and experimental engine exhaust gas emissions [32].

\begin{tabular}{llcccc}
\hline Results (g/Kg. fuel) & & NOx & PM & CO & UHC \\
\hline \multirow{2}{*}{ PDC } & Experimental & - & 0.3 & 6.3 & - \\
& CFD Simulation & 38.4 & 0.22 & 6.9 & 0.95 \\
\hline \multirow{2}{*}{ DSC } & Experimental & 43.1 & 0.0037 & - & - \\
& CFD Simulation & 46.4 & 0.006 & 24.61 & 1.91 \\
\hline
\end{tabular}


This research aims to investigate the effects of using post-injection of diesel fuel and the addition of syngas $\left(\mathrm{H}_{2}-\mathrm{CO}\right.$ gaseous mixture) to the combustion chamber in a heavy-duty DI diesel engine. Influence of 36 strategies based on postinjection characteristics such as main-post dwell time (post-injection and main-injection timing), fuel quantity, and spraying pressure on the combustion characteristics (in-cylinder temperature, HRR, combustion phase, and HCE), exhaust gas emissions (NOx, PM, UHC, and CO), and performance (ITE) at PDC and DSC engine operating conditions were separately studied. Table 6 shows the applied strategies for diesel fuel injection.

Table 6. Fuel injection strategies

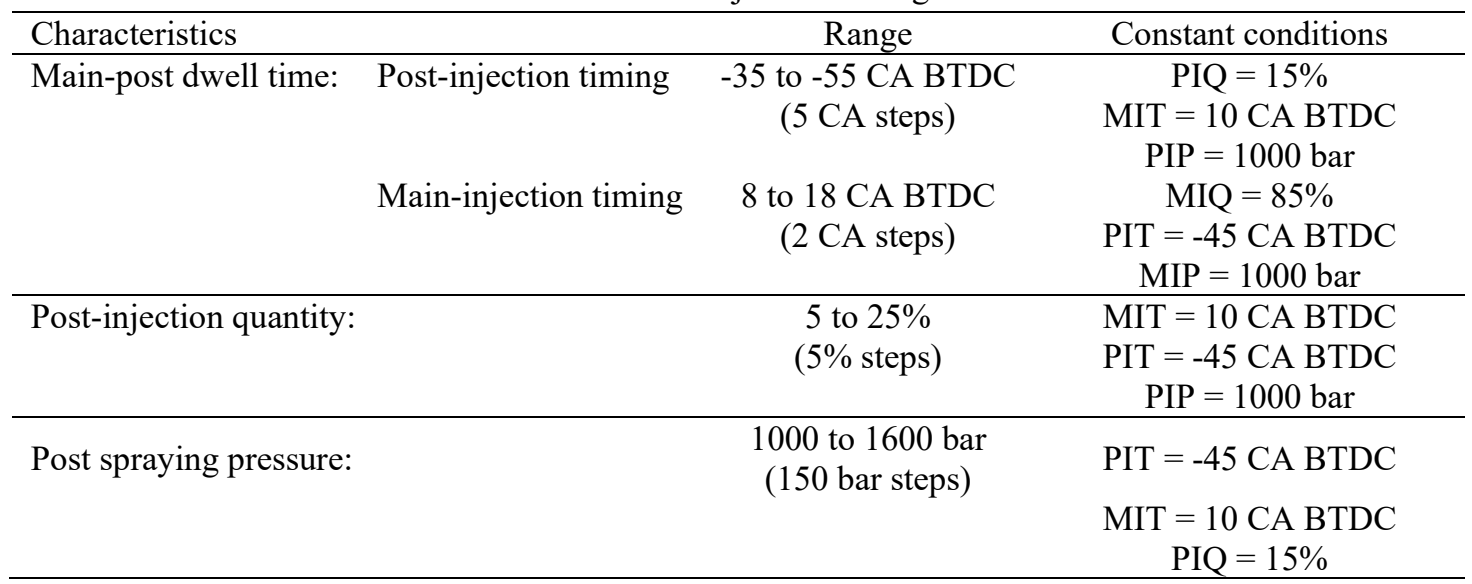

\section{Definitions}

i. CA5, CA10, CA50, and CA90: Are the crank angle of 5, 10, 50, and 90\% of total fuel per cycle burned, respectively.

ii. Combustion duration: Difference between CA90 and CA10.

iii. Ignition delay: Difference between CA5 and SOI.

iv. Hydrogen combustion efficiency: $\eta_{\mathrm{H}_{2}}=1-\left(m_{\mathrm{H}_{2}}^{E V O} / m_{H_{2}}^{I V C}\right)$

where $m_{H_{2}}^{E V O}$ and $m_{H_{2}}^{I V C}$ are the mass of hydrogen gas at EVO and IVC, respectively.

\section{RESULTS AND DISCUSSION}

\section{Influence of Main-Post Dwell Time}

\section{Post-injection timing}

Figure 3 shows the simultaneous effects of syngas addition and post-injection timing on the burning timings, heat release rate, in-cylinder mean temperature and hydrogen gas combustion efficiency. As can be seen from Figure 3(a), replacing $40 \%$ of diesel fuel with $\mathrm{CO}-\mathrm{H}_{2}$ gaseous mixture led to a shorter ID period and combustion duration compared to PDC mode. As indicated in Table 4, because of the significant low energy requirement for auto-ignition and higher flame velocity of hydrogen gas, CA5 noticeably advanced and resulted in a shorter ID period compared to neat diesel combustion mode at constant MIT. Also, because of the shorter fuel injection duration as a result of less fuel per cycle at DSC mode, CA50 and CA90 noticeably advanced and resulted in shorter combustion duration compared to the PDC operating case. Late injection of diesel fuel slightly affected CA5, CA10, and CA50 due to shorter main-injection duration at both PDC and DSC modes. However, retarding post-injection timing resulted in a more extended combustion duration since CA90 noticeably postponed.

Figure 3(b) shows the impacts of syngas addition and post-injection timing on the in-cylinder heat release rate. As can be seen from Figure 3(b), syngas addition caused a higher HRRPP for the main combustion event compared to PDC mode. Significant higher flame speed and heating value (mentioned in Table 4) of $\mathrm{H}_{2}$ gas led to more heat to release by a rapid burning rate during a shorter period compared to neat diesel combustion. Also, as indicated in this figure, higher incylinder oxygen concentration under DSC conditions can enhance air-fuel mixture oxidation, and consequently, the flame temperature can be increased. Thus, as illustrated in Figure 3(b), HRRPP noticeably increased compared to PDC engine operating conditions. However, for the second combustion event caused by diesel post-injection, late HRR during expansion stroke under PDC conditions is higher compared to DSC mode for all PITs. This can be attributed to the higher amount of diesel mass at PDC case, which significantly increased HRR during expansion stroke and, as a result enhanced second combustion event compared to the DSC mode. Post-injection of diesel fuel due to less heat release during the main combustion event accompanied by lower HRRPP (main combustion event HRR) under both PDC and DSC conditions compared to the baseline single-stage diesel injection modes. In addition to that, retarding post-injection timing caused lower HRRPP for the second fuel injection pulse due to a sharp decrease in pressure and temperature during the expansion stroke. Hence, as indicated in Figure 3(b), by retarding post-injection timing the mixture oxidation process for the second fuel injection event has weakened and resulted in lower HRRPP compared to early PITs. 
As can be seen from Figure 3(c), 40\% substitution of diesel fuel with syngas significantly increased combustion temperature as a result of higher AFR and temperature rise rate compared to PDC mode. Also, using post-injection resulted in lower TPP due to less fuel quantity for the main-injection event compared to the single-stage fuel spraying strategy. Furthermore, double-injection of diesel fuel caused a two-stage peak point for the in-cylinder mean temperature trend. However, because of the sharp decrease in pressure and temperature inside the combustion chamber after the TDC point, retarding post-injection timing is along with a lower maximum temperature for the second peak point. Figure 3(d) reports the influence of post-injection timing on hydrogen combustion efficiency at DSC mode. As indicated in Figure 3 (d) double injection strategy resulted in less HCE due to lower in-cylinder TPP and more unburnt $\mathrm{H}_{2}$ at the exhaust gas. Retarding post-injection timing also has more adverse effects because of lower in-cylinder temperature during the expansion stroke, causing inefficient oxidation of remained unburnt hydrogen gas from the main combustion event.

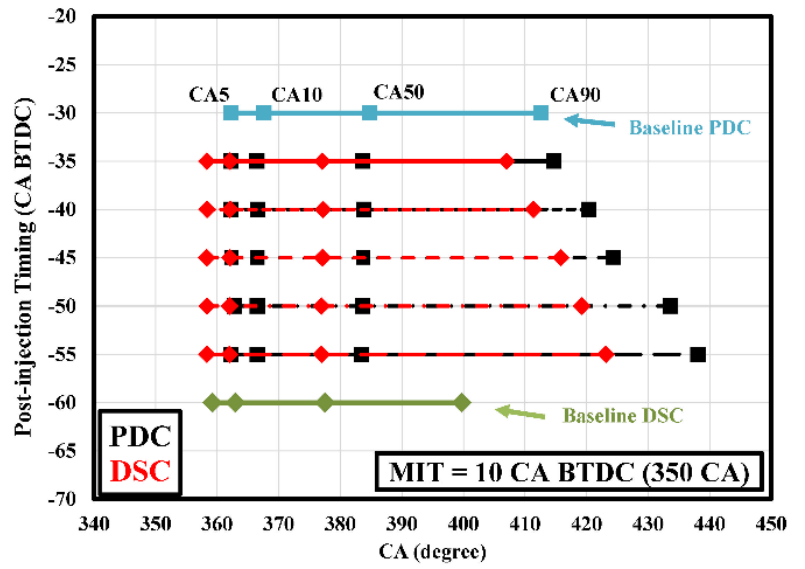

(a) Burning timings

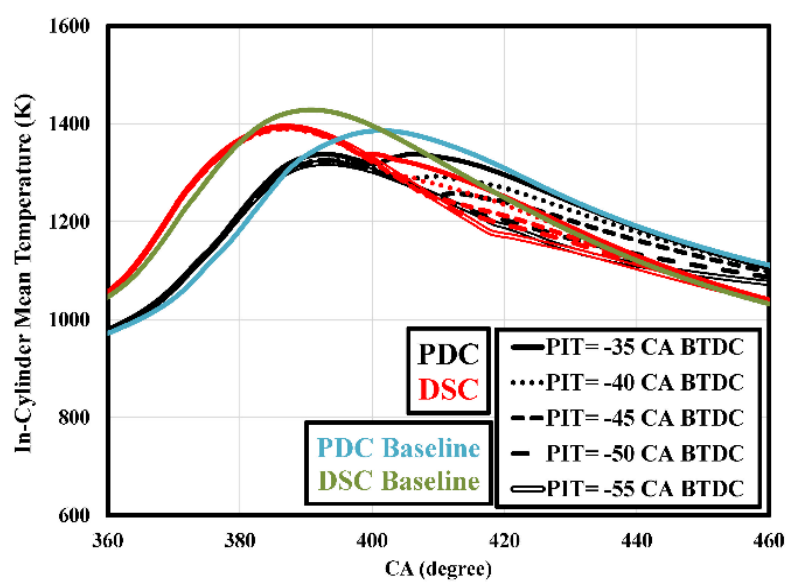

(c) In-cylinder mean temperature

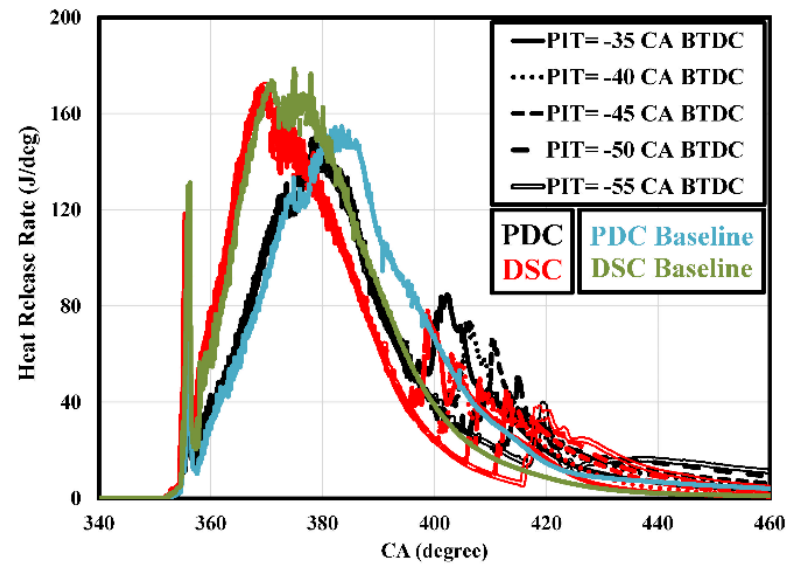

(b) HRR

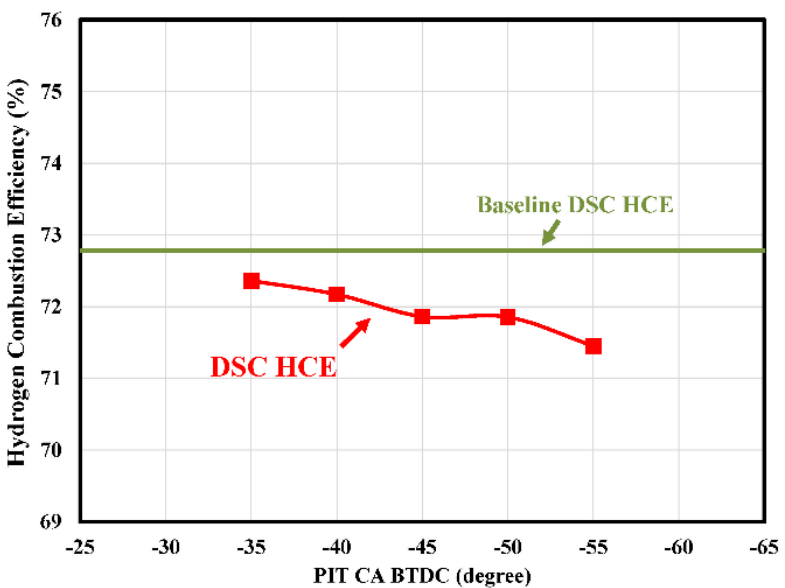

(d) HCE

Figure 3. Effects of post-injection timing and syngas addition on the (a) Burning timings, (b) HRR, (c) In-cylinder mean temperature, and (d) HCE.

Figure 4 shows the effects of post-injection timing and syngas addition on NOx, PM, CO, and UHC emissions. As can be seen from Figure 4(a), the addition of syngas into the combustion chamber increased NOx emissions as a result of higher in-cylinder temperature compared to PDC mode. Also, using the post-injection strategy caused lower NOx emissions at exhaust gases due to decreased in-cylinder TPP. By retarding post-injection timing at DSC and PDC modes, NOx noticeably decreased as a result of a sharp decrement of pressure and temperature inside the combustion chamber during the expansion stroke and also significant low oxygen concentration for the second fuel mixture formation. In addition to that, by substitution of $40 \%$ of diesel fuel with syngas, PM emission considerably diminished as a result of higher AFR, lower carbon content participating in the dual-fuel combustion process, and higher in-cylinder TPP. At the PDC condition, by retarding PIT, PM formation dramatically increased as a result of lower in-cylinder temperature for late post-injection timings and less oxygen available for the second mixture formation. However, at DSC mode, retarding post-injection has negligible effects on PM formation, which can be due to higher AFR and less fuel quantity for the second injection event compared to PDC condition.

As illustrated in Figure 4(b), the addition of syngas considerably increased $\mathrm{CO}$ emission since half of the syngas volume itself was composed of CO gas. Under PDC engine operating conditions, it can be seen from Figure 4(b) that retarding post-injection timing vastly increased $\mathrm{CO}$ emission, which can be due to lower in-cylinder temperature and oxygen concentration that resulted in inefficient air-fuel mixture formation for the post-injection. As indicated in Figure 4(b), the amount of UHC emissions are near zero under both PDC and DSC conditions. However, using post-injection 
and retarding its timing under PDC conditions dramatically increased the UHC level as a result of low in-cylinder temperature during expansion stroke and less available oxygen for sufficient air-fuel mixture formation, which led to more diesel fuel misfire during engine operating. Also, at DSC mode, it can be seen from Figure 4(b) that due to high AFR and less fuel quantity, retarding PIT has negligible adverse impacts on UHC emissions. However, for very late postinjection timing (e.g., -55 CA BTDC), UHC increased, which can be related to inferior mixture formation and more diesel misfire.

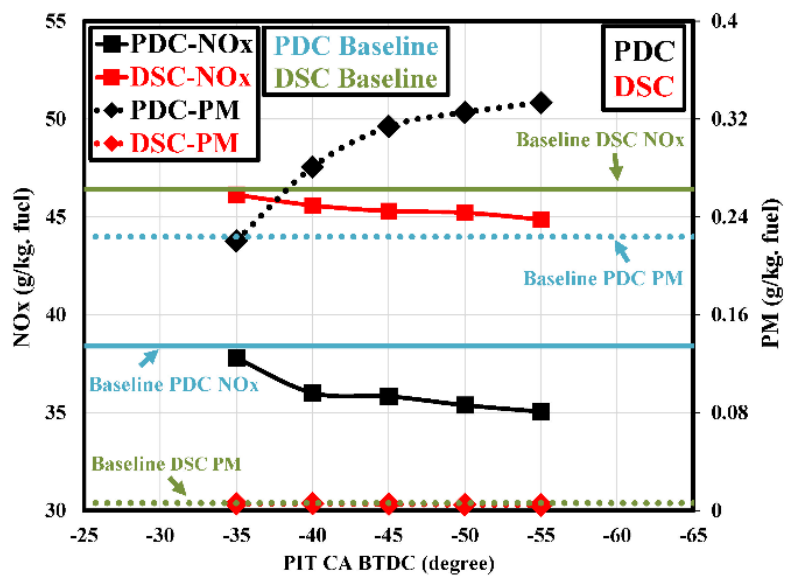

(a) NOx and PM vs. PIT

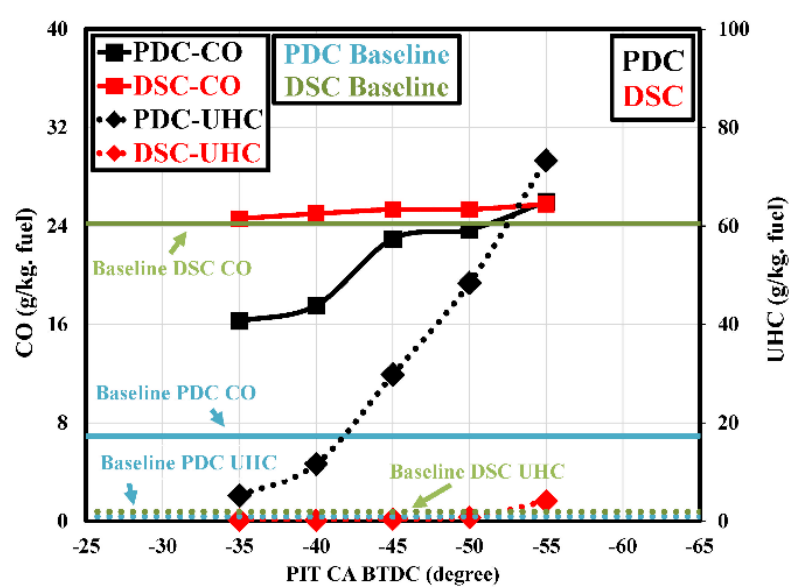

(b) $\mathrm{CO}$ and UHC vs. PIT

Figure 4. Effects of post-injection timing and syngas addition on (a) NOx-PM and (b) CO-UHC emissions.

Figure 5 illustrates the effects of syngas fuel addition and post-injection timing on the indicated thermal efficiency. As can be seen in this figure, ITE is slightly enhanced by the addition of syngas fuel into the combustion chamber compared to the PDC operating conditions due to the advanced CA50 timing to the TDC point and higher flame temperature (HRRPP). However, by retarding the PIT, ITE deteriorated for both PDC and DSC cases as the result of a gradual decrement of in-cylinder pressure and temperature during expansion movement of the combustion chamber. In addition, at PIT of -35 CA BTDC, ITE noticeably improved under PDC and DSC conditions. This can be attributed to the higher temperature of the second combustion event that can increase expansion stroke utilisation compared to the late PITs.

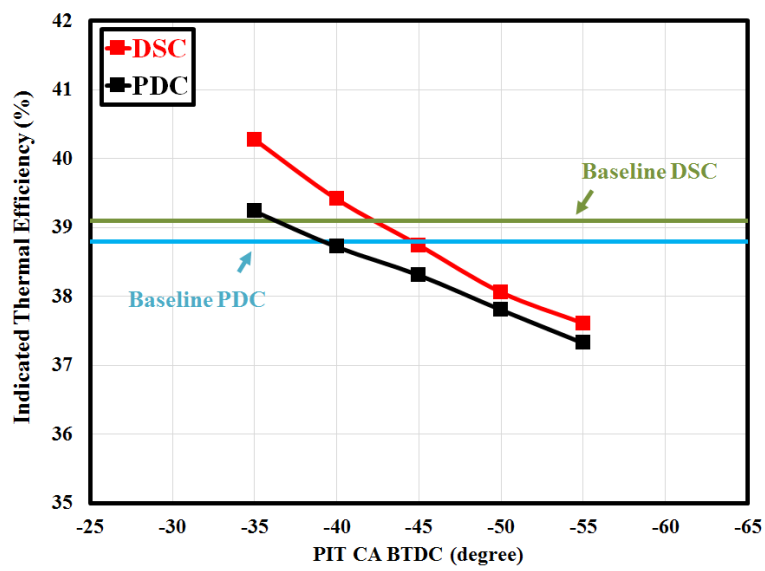

Figure 5. ITE vs. PIT under PDC and DSC operating conditions.

\section{Main-injection timing}

Figure 6 shows the influence of main-injection timing on the burning timings, heat release rate, in-cylinder mean temperature and hydrogen combustion efficiency under PDC and DSC conditions. As can be seen from Figure 6(a), advancing main-injection timing prolonged the ID period as a result of lower in-cylinder pressure and temperature at early MITs under PDC and DSC conditions. Also, at the constant PIT, advanced main fuel injection event increased combustion duration as a result of a prolonged interval between CA50 and CA90. Figure 6(b) reports the effects of maininjection timing on HRR. As can be seen from this figure, advancing MIT increased HRRPP as a result of more amount of diesel fuel evaporated and accumulated during the ID period. In other words, for a more extended ID period, more portion of air-fuel mixture burns in premixed combustion mode, and as a result, more fuel ignites at once, accompanied by higher HRRPP. However, postponing main-injection timing resulted in lower HRRPP. By retarding MIT due to higher in-cylinder pressure and temperature near the end of the compression stroke, the ID period became shorter at late MITs and resulted in more fuel burns in diffusive combustion. In other words, for a shorter ID period, less evaporated fuel accumulated and resulted in less portion of air-fuel mixture auto-ignites at once. Thus, as can be seen from Figure 6(b), 
retarding main-injection timing decreased the portion of air-fuel premixed combustion and led to lower HRRPP at PDC and DSC modes. Furthermore, by looking at the presented results in Figure 6(b), it can be seen that by advancing MIT, HRRPP for post-injection decreased. It can be concluded that by advancing main-injection timing due to prolonged combustion duration, the air-fuel oxidation process for the second fuel injection event weakened and was accompanied by a lower heat release rate.

Figure 6(c) shows the influence of main-injection timing on in-cylinder mean temperature under PDC and DSC engine operating conditions. As can be seen from Figure 6(c), by advancing main-injection timing, TPP increased but, postponing MIT resulted in lower TPP. It can be concluded that by advancing the main-injection timing, more portion of evaporated fuel burnt in premixed combustion. Hence, due to the rapid burning rate of the accumulated air-fuel mixture during a more extended ID period, the in-cylinder temperature rise rate significantly increased and resulted in higher TPP. However, due to an increase in the portion of air-fuel diffusion combustion caused by postponing MIT, the in-cylinder temperature rise rate decreased and led to lower TPP. Furthermore, as can be seen from Figure 6(c), by advancing maininjection timing, in-cylinder mean temperature for the second fuel injection event decreased, which can be due to longer combustion duration that caused lower temperature rise rate for the second combustion event. Figure 6(d) reports the impacts of main-injection timing on hydrogen combustion efficiency. As illustrated in Figure 6(d), by advancing MIT, HCE was enhanced as a result of higher TPP. However, retarding MIT caused deteriorated HCE due to more portion of evaporated fuel burnt in diffusive combustion and led to lower TPP. From Figure 6(d), it can be concluded that an increase in the portion of air-fuel premixed combustion leads to higher flame temperature and, as a result, flame propagation enhanced. Hence, air-fuel mixture oxidation has improved, and less unburnt mixture such as hydrogen gas can be observed in the exhaust gas.

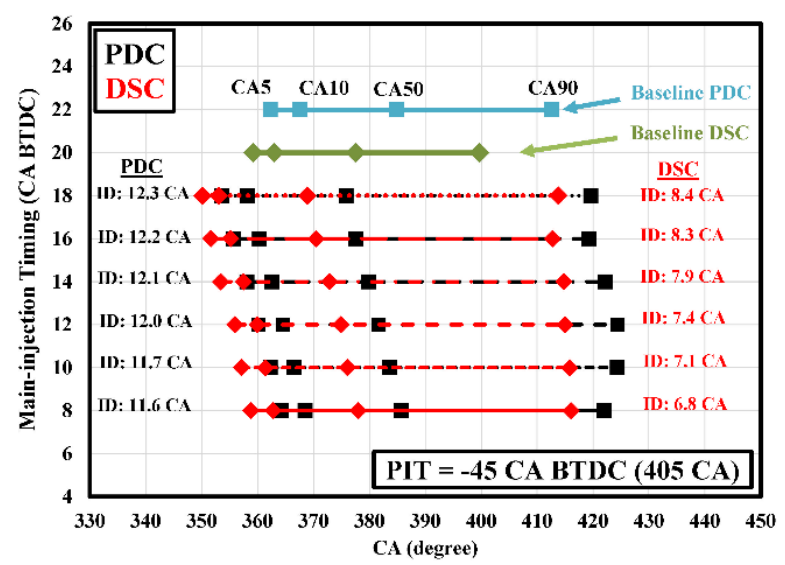

(a) Burning timings

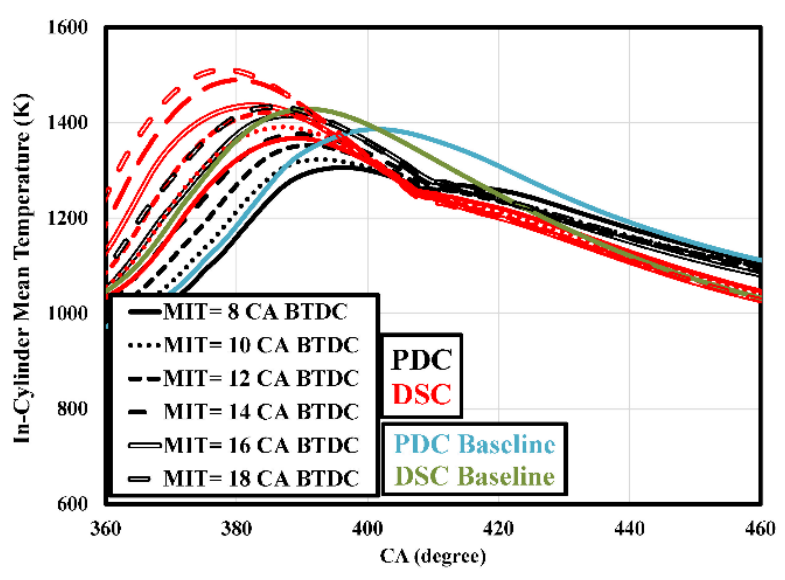

(c) In-cylinder mean temperature

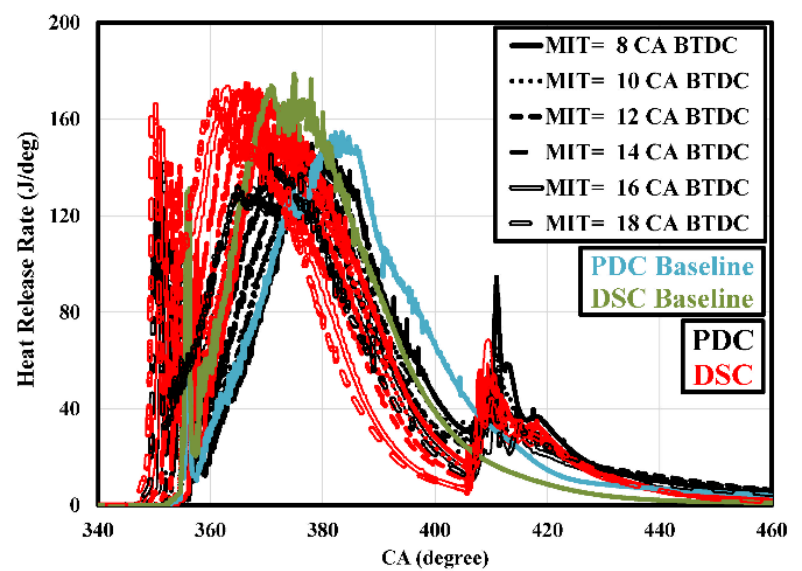

(b) HRR

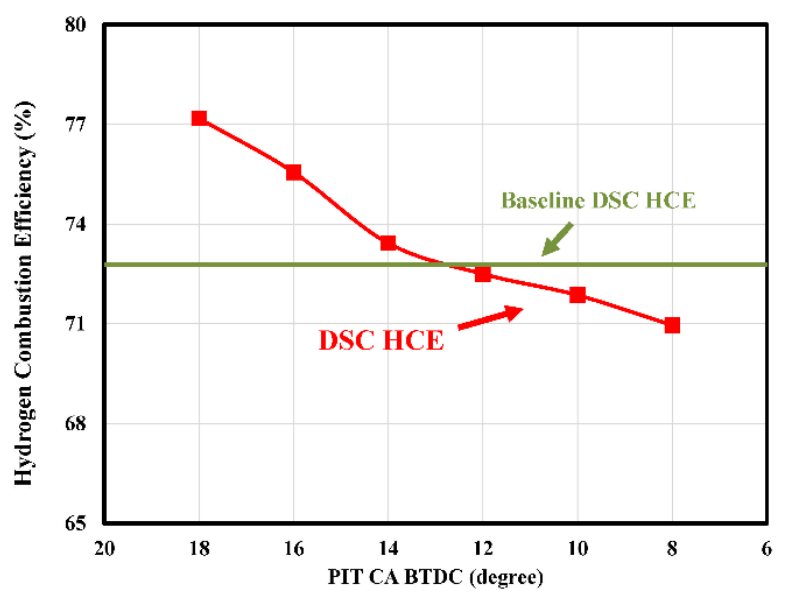

(d) $\mathrm{HCE}$

Figure 6. Effects of main-injection timing on (a) Burning timings, (b) HRR, (c) In-cylinder mean temperature, and (d) HCE.

Figure 7 shows the effects of main-injection timing on NOx, PM, CO, and UHC emissions. As can be seen from Figure 7(a), advancing MIT increased NOx emissions as a result of a prolonged ID period that is accompanied by more available time for nitrogen species oxidation and also higher TPP at both PDC and DSC modes. Also, as illustrated in Figure 7(a), PM emission was diminished by advancing MIT under PDC engine operating conditions. As mentioned earlier, the advanced main fuel injection event accompanied by a more extended ID period, which resulted in higher TPP. Hence, the air-fuel mixture oxidation process enhanced and caused less PM in the exhaust gas. Also, longer ID has more positive effects on PM oxidation by providing more time for efficient oxidation of carbon species inside the combustion 
chamber. Furthermore, as reported in Figure 7(a), at DSC mode, MIT has a minor impact on PM emissions due to significant high AFR and lower carbon content participating in the combustion process (as a result of substitution $40 \%$ of diesel fuel with syngas) that leads to reduce PM near zero.

As illustrated in Figure 7(b), advancing main-injection timing is accompanied by lower CO and UHC as a result of higher TPP and also a more extended ID period. In addition, at DSC mode, main-injection timing has ignorable impacts on UHC, which can be due to the replacing part of diesel fuel with syngas that significantly decreased carbon content participating in the combustion process. From Figure 6, it can be concluded that by an increase in the portion of premixed combustion and enhanced flame propagation, air-fuel mixture oxidation improved. Thus, due to less diesel misfire, carbon-based emissions such as PM, CO, and UHC noticeably decreased. However, because of the higher combustion temperature caused by the enhanced flame propagation throughout the combustion chamber, NOx emissions increased.

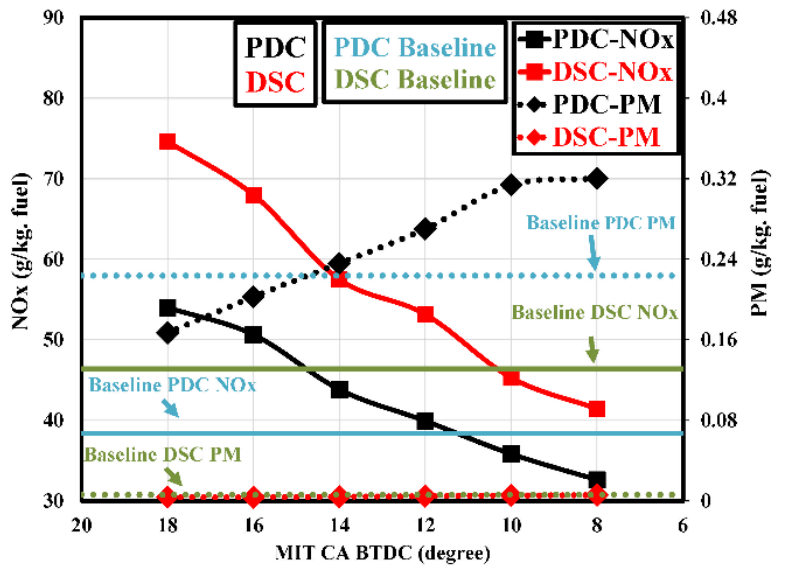

(a) NOx and PM vs MIT

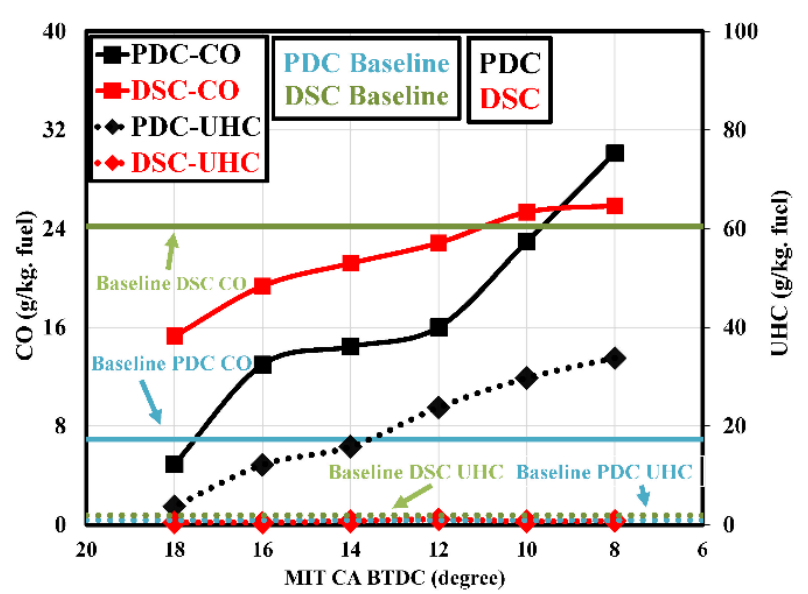

(b) $\mathrm{CO}$ and UHC vs MIT

Figure 7. Effects of main-injection timing on (a) NOx-PM and (b) CO-UHC.

Figure 8 shows the in-cylinder equivalence ratio at PDC and DSC modes. As illustrated in Figure 8, under the PDC condition, regions with a high equivalence ratio can be seen near the nozzle area, the bottom of the bowl, the squish area, and near the cylinder wall. Because of more diesel fuel compared to DSC mode, more diesel can widely distributing inside the combustion chamber and led to more lean air-fuel mixture formation. Also, due to the more extended ID period and fuel spraying duration under PDC conditions, more fuel can reach cylinder wall and crevice regions. Thus, because of more regions with lower AFR inside the combustion chamber compared to DSC conditions, more carbon-based emissions such as PM and UHC can be seen in the exhaust gases at PDC mode as a result of the weakened air-fuel mixture oxidation process.

Figure 9 shows the in-cylinder temperature under PDC and DSC conditions where more regions with higher temperatures can be seen at DSC compared to PDC mode. The addition of syngas into the combustion chamber due to containing hydrogen and also higher AFR compared to PDC conditions led to higher combustion temperature. Moreover, by comparing Figure 8 and Figure 9 at DSC mode, it can be seen that regions with a lower equivalence ratio also have a higher temperature. Hence, it can be concluded that the $40 \%$ substitution of diesel fuel with syngas, accompanied by improved air-fuel mixture formation. Thus, mixture oxidation enhanced and led to higher combustion temperature that caused lower PM and UHC emissions. However, more NOx formed compared to PDC conditions.

Figure 10 depicts the impacts of main-injection timing on the ITE under PDC and DSC operating conditions. According to this figure, as MIT was advanced from 8 to 18 CA BTDC, ITE is significantly enhanced by nearly $1.9 \%$ and 3.9\% under PDC and DSC cases compared to the baseline operating conditions, respectively. This can be attributed to the advanced CA50 timing to the TDC point and thus, increased TPP, which led to improved air-fuel mixture oxidation and better fuel economy.

\section{Influence of post-injection quantity}

Figure 11 reports the effects of post-injection quantity on the burning timings, heat release rate, in-cylinder mean temperature and hydrogen combustion efficiency. As can be seen from Figure 11(a), increasing post-injection quantity accompanied by advanced CA5, CA10, and CA50 as a result of shorter main fuel injection duration. Also, CA90 is considerably retarded since more fuel is devoted to the second fuel injection event. Thus, as illustrated in Figure 11(a), the ID period shortened, and combustion duration prolonged under PDC and DSC engine operating conditions. Figure 11(b) reports the post-injection quantity on the heat release rate. As can be seen from Figure 11(b), increasing postinjection quantity accompanied by lower HRRPP as a result of less fuel for main-injection that led to less heat to release during the main combustion event. Also, the second HRRPP increased that attributed to higher post-injection quantity. In addition, by comparing HRR trends for both engine operating conditions, it can be seen that at PDC mode, first and second HRRPP are higher than DSC conditions which is related to higher fuel quantity per cycle and, consequently more heat released during the second combustion event. 


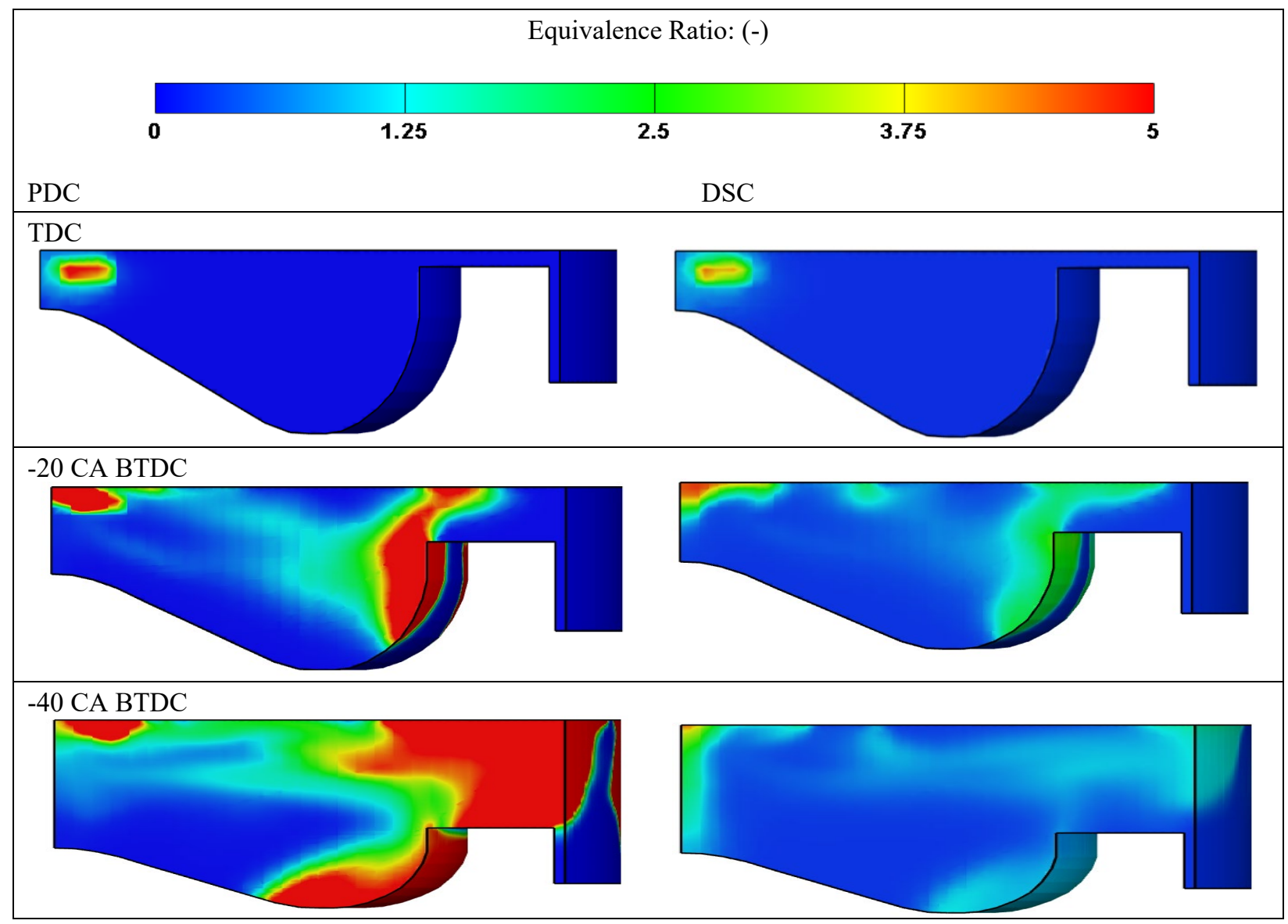

Figure 8. Effect of syngas addition on in-cylinder equivalence ratio.

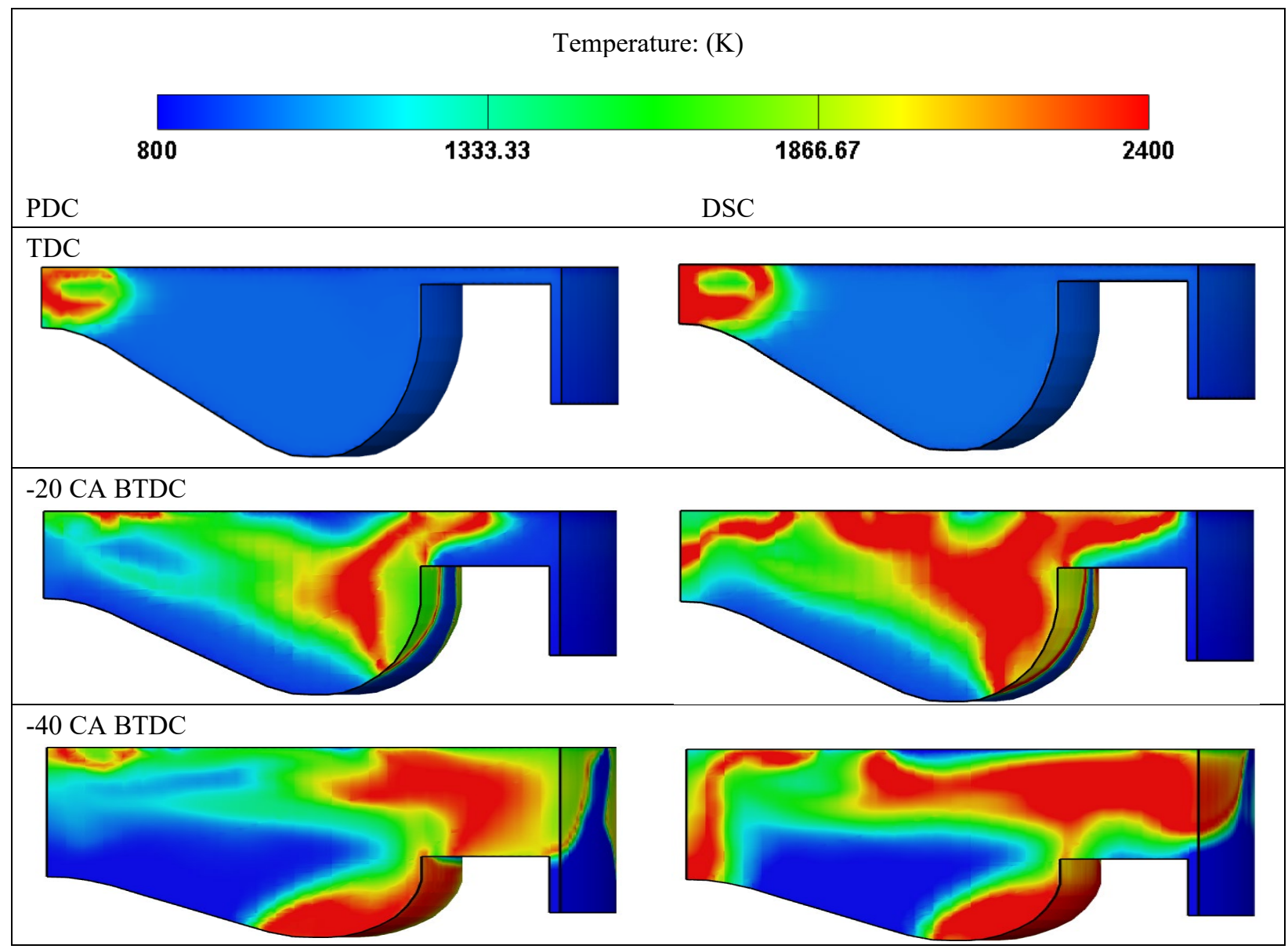

Figure 9. Effect of syngas addition on in-cylinder temperature. 


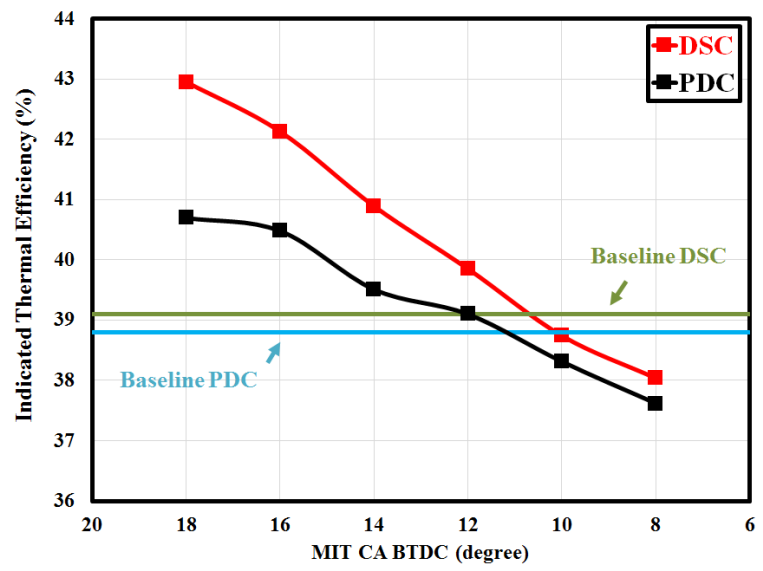

Figure 10. Impacts of MIT on ITE under PDC and DSC operating conditions.

Figure 11(c) illustrates the influence of post-injection quantity on the in-cylinder mean temperature at PDC and DSC modes. As can be seen from Figure 11(c), by increasing PIQ, the maximum combustion temperature reduced. However, the combustion temperature for the second fuel injection event increased. This trend infers that by increasing PIQ, the flame temperature of the second combustion event increased and caused a higher cylinder-out gas temperature. The impacts of post-injection quantity on hydrogen combustion efficiency under DSC engine operating conditions are shown in Figure 11(d). According to this figure, by increasing post-injection quantity up to $15 \%$, HCE initially decreased, then improved at 20 and $25 \%$ PIQ. It can be concluded that by increasing post-injection quantity up to $15 \%$, due to lower incylinder TPP, the portion of the unburnt mixture increased and resulted in more hydrogen in the exhaust gases. However, by devoting more fuel to the second injection pulse (e.g., 20 and $25 \%$ of total fuel per cycle), due to higher flame temperature and heat release rate; mixture oxidation is enhanced. This may be attributed to the higher flame temperature of the second combustion event, which re-oxidised the unburnt mixture remained from the main combustion event. Thus, as can be seen from Figure 9(d), the amount of engine-out hydrogen gas decreased at 20 and 25\% PIQ.

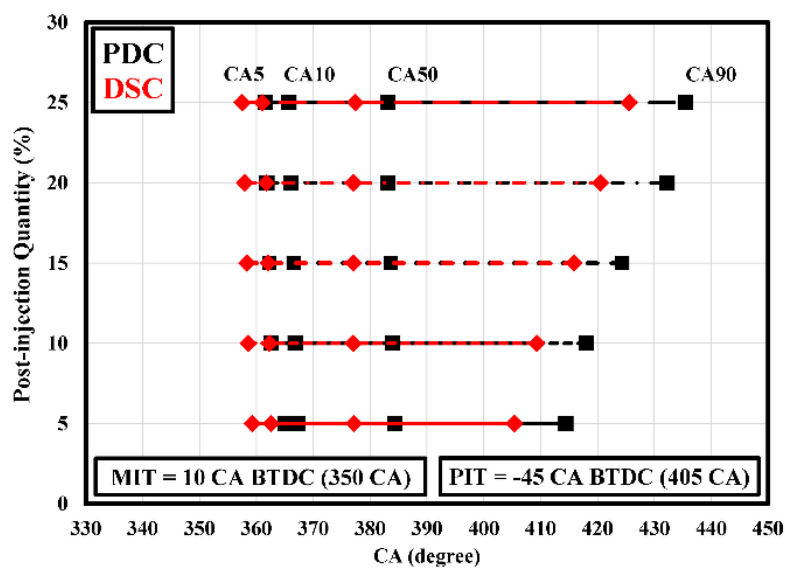

(a) Burning timings

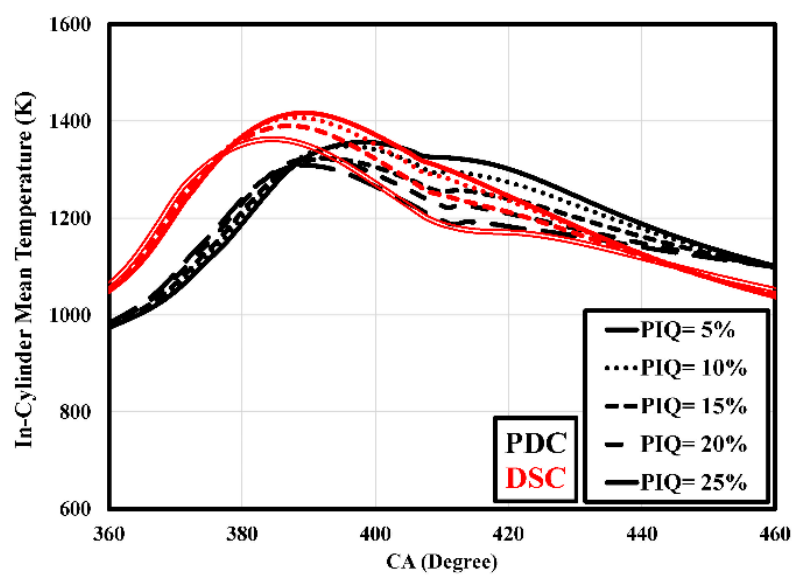

(c) In-cylinder mean temperature

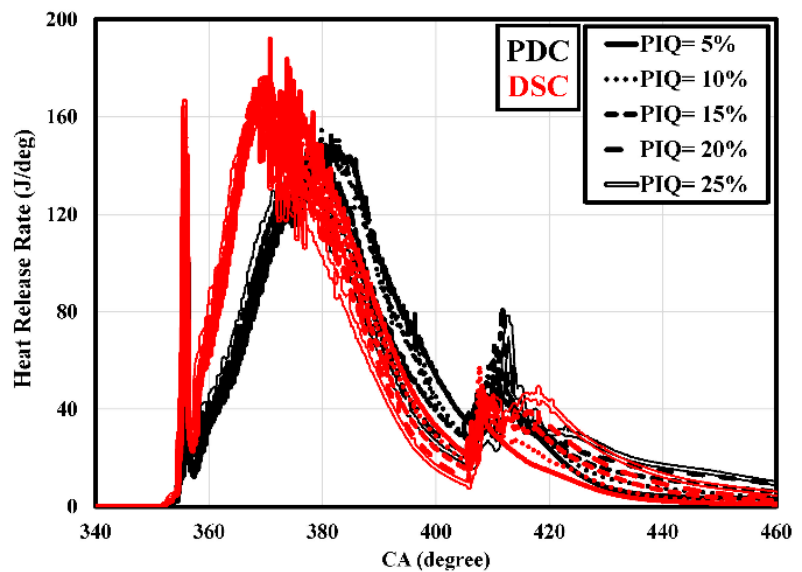

(b) HRR

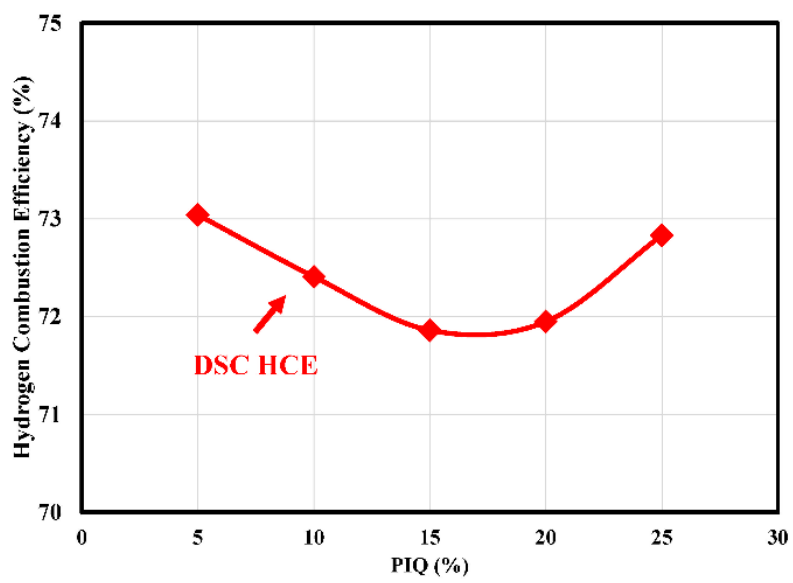

(d) $\mathrm{HCE}$ 
Figure 11. Effects of post-injection quantity on (a) Burning timings, (b) HRR, (c) In-cylinder mean temperature, and (d) HCE.

Figure 12 illustrates the effects of post-injection quantity on NOx, PM, CO, and UHC emissions under PDC and DSC engine operating conditions. As can be seen from Figure 12(a), increasing post-injection quantity up to $15 \%$ caused lower NOx formation as a result of lower TPP. However, devoting more fuel to the post-injection (e.g., 20 and $25 \%$ ) slightly increased NOx that can be attributed to higher exhaust gas temperature that enhanced thermal NOx formation during the expansion stroke. According to Figure 12(a), because of the lower temperature of the main combustion event caused by increasing PIQ up to $15 \%$, more PM was observed in the exhaust gases under PDC condition. This can be related to lower main combustion quality caused by deteriorated mixture oxidation. However, for 20 and 25\% PIQ, PM formation slightly diminished due to the higher flame temperature of the second combustion event. Also, based on the results presented in Figure 12(a) under the DSC condition, PIQ has ignorable impacts on PM formation. This can be due to higher AFR and also lower carbon content participating in the combustion that decreased the adverse influence of post-injection on PM formation.

Figure 12(b) shows the effects of post-injection quantity on CO and UHC formation. Increasing PIQ resulted in more $\mathrm{CO}$ and UHC emissions due to lower in-cylinder oxygen concentration for the second mixture formation during the expansion stroke. Also, because of lower in-cylinder pressure and temperature after the TDC point, spray tip penetration can be increased, and more fuel can reach the cylinder wall and crevices. Thus, as can be seen from Figure 12(b), CO and UHC emissions noticeably increased by the addition of PIQ due to more diesel fuel misfire. Furthermore, for DSC mode, by increasing PIQ, less CO and UHC formed compared to PDC mode. This can be related to less post-injection quantity at DSC conditions that prevented more $\mathrm{CO}$ and UHC formation during the second combustion event.

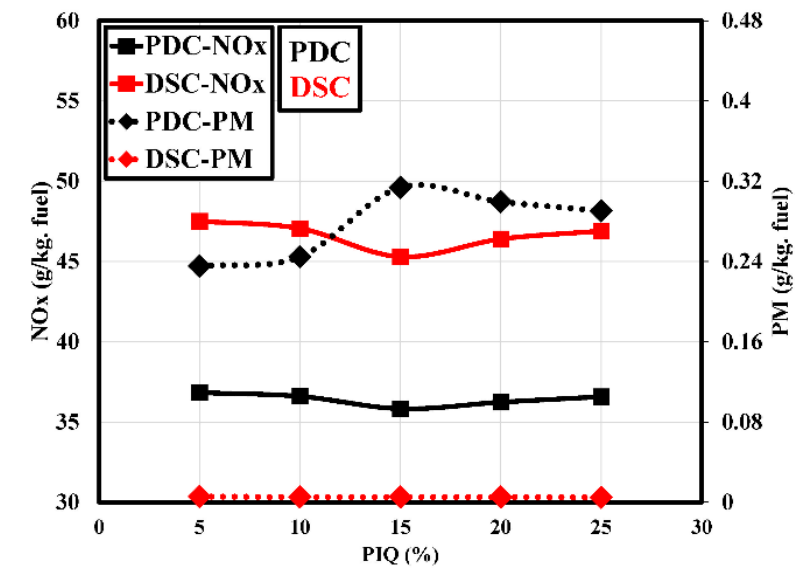

(a) NOx and PM vs. PIQ

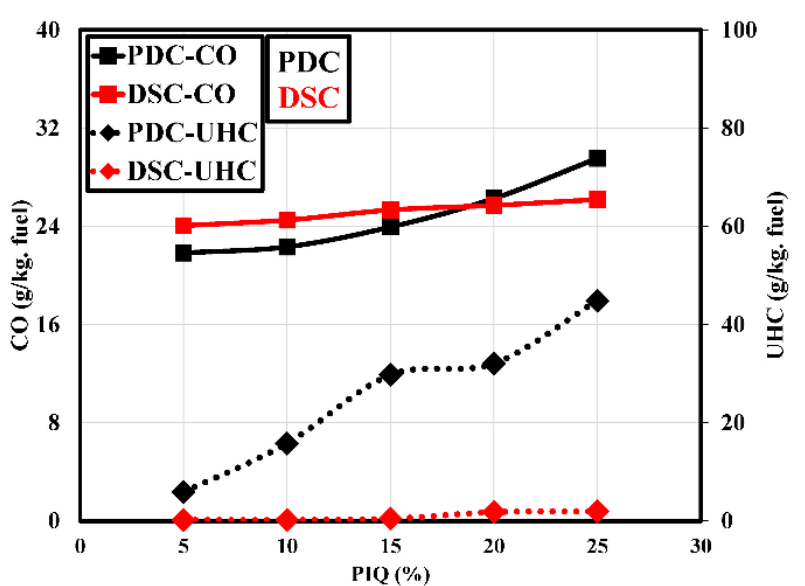

(b) $\mathrm{CO}$ and UHC vs. PIQ

Figure 12. Effects of post-injection quantity on (a) NOx-PM and (b) CO-UHC.

Figure 13 indicates the effects of post-injection quantity on indicated thermal efficiency under PDC and DSC operating modes. As shown in this figure, by increasing PIQ from $5 \%$ to $25 \%$, ITE dramatically decreased under all engine operating conditions. This is due to the reduction of the main fuel injection quantity and devoting a specific part of it to the second fuel injection event, which led to the decrement of in-cylinder TPP and deteriorated air-fuel oxidation process. Therefore, the main combustion event weakened and resulted in an overall reduction of engine performance.

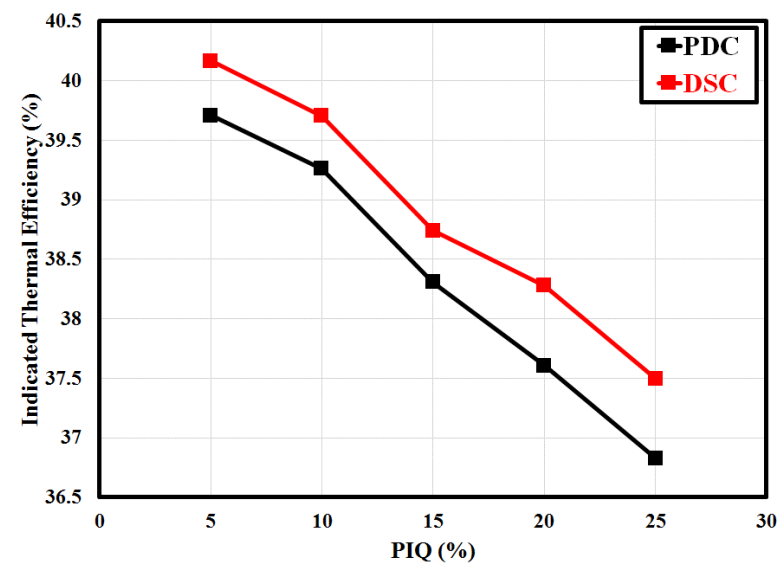

Figure 13. ITE vs PIQ at PDC and DSC engine operating conditions. 


\section{Influence of Post-Injection Pressure}

Impacts of post-injection pressure on the burning timings, heat release rate, in-cylinder mean temperature, and hydrogen combustion efficiency is shown in Figure 14. As can be seen from Figure 14(a), by increasing post-injection pressure under PDC and DSC conditions, CA90 advanced, and as a result, combustion duration shortened. However, as indicated in Figure 14(a), at 1600 bar PIP under PDC condition, CA90 noticeably retarded and caused a more extended combustion duration. Figure 14(b) shows the effects of post-injection pressure on the heat release rate under both PDC and DSC conditions. Based on Figure 14(b), increasing PIP caused higher HRRPP of the second combustion event. This can be attributed to the fact that higher PIP led to enhanced mixture formation; thus, more heat released during the second combustion event. According to Figure 14(b), by comparing the trends for both engine operating conditions, unlike DSC mode, 1600 bar PIP caused lower HRRPP for the late combustion event under PDC condition. It can be concluded that due to lower AFR at PDC mode that accompanied by low oxygen concentration near the nozzle area and also shorter spray tip penetration at 1600 bar PIP, more portion of post-injection fuel experienced in-complete oxidation. Thus, combustion duration became more extended (retarded CA90 timing) and HRRPP of the second combustion event decreased.

Figure 14(c) shows the influence of the post-injection pressure on the in-cylinder mean temperature. As can be seen from Figure 14(c), by increasing PIP under PDC and DSC operating conditions, TPP for the second combustion event increased. This can be related to higher flame temperature caused by enhanced mixture oxidation. However, according to Figure 14(c), at 1600 bar PIP under the PDC engine operating condition, the temperature peak point for the late combustion event decreased. That can be due to shorter spray tip penetration and lower oxygen concentration near the nozzle area, which deteriorated the late combustion quality. Figure 14(d) illustrates the impacts of post-injection pressure on HCE under the DSC operating condition. As can be seen from Figure 14(d) by increasing PIP due to an increase in the second flame temperature and enhanced mixture oxidation, hydrogen combustion efficiency increased. In other words, by increasing post-injection pressure, the temperature peak point for the second combustion event increased and led to unburnt mixtures remained from the main combustion event to partially re-oxidise again. Thus, HCE slightly enhanced and less hydrogen is observed in the exhaust gases.

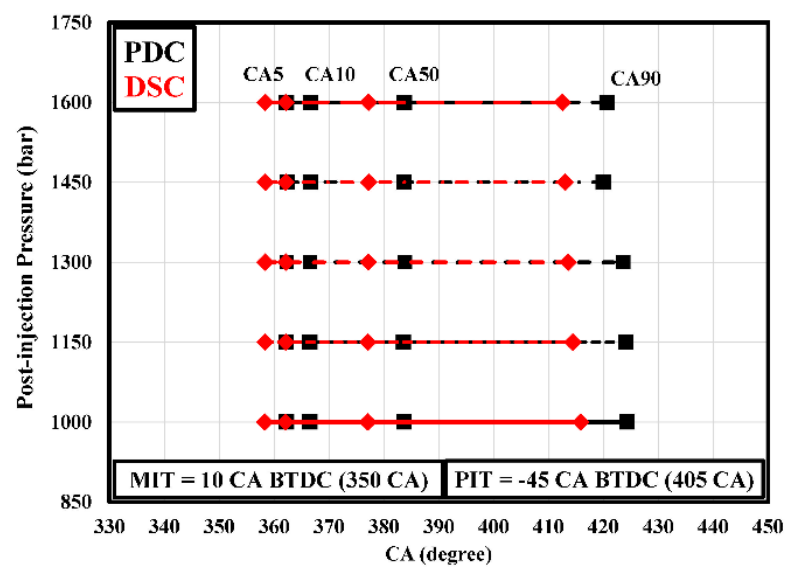

(a) Burning timings

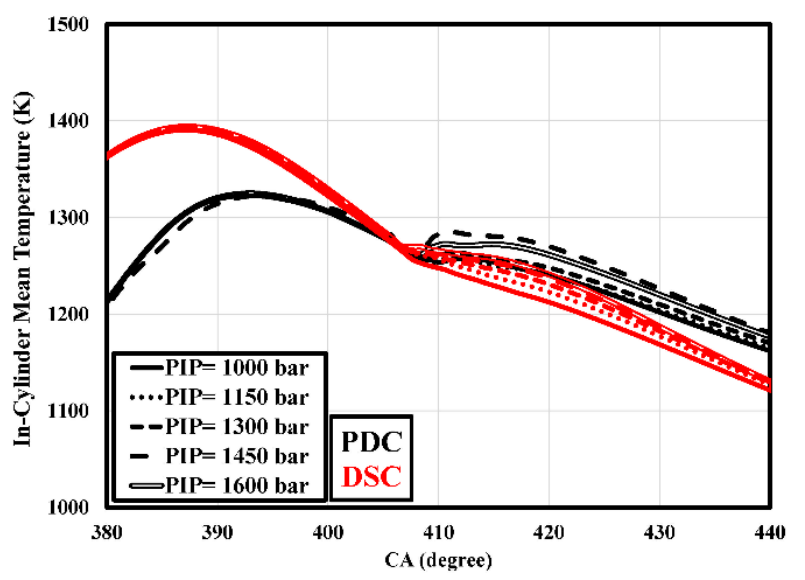

(c) In-cylinder mean temperature

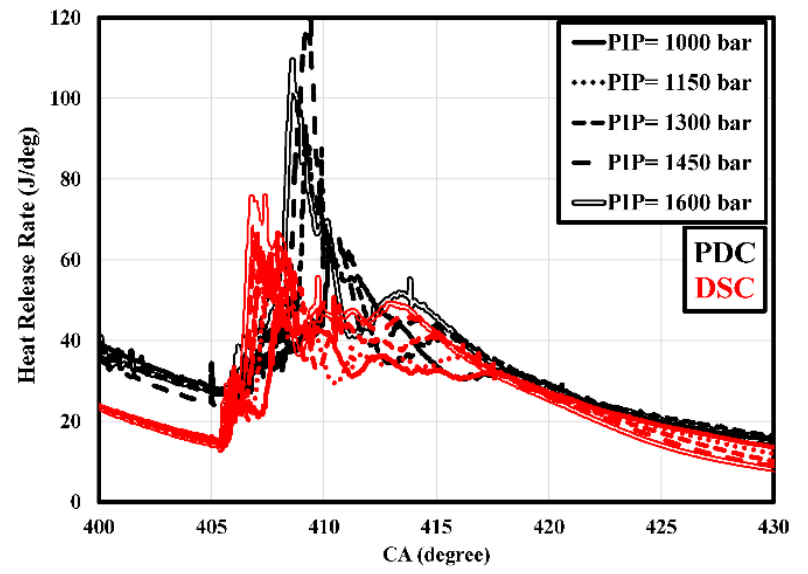

(b) HRR

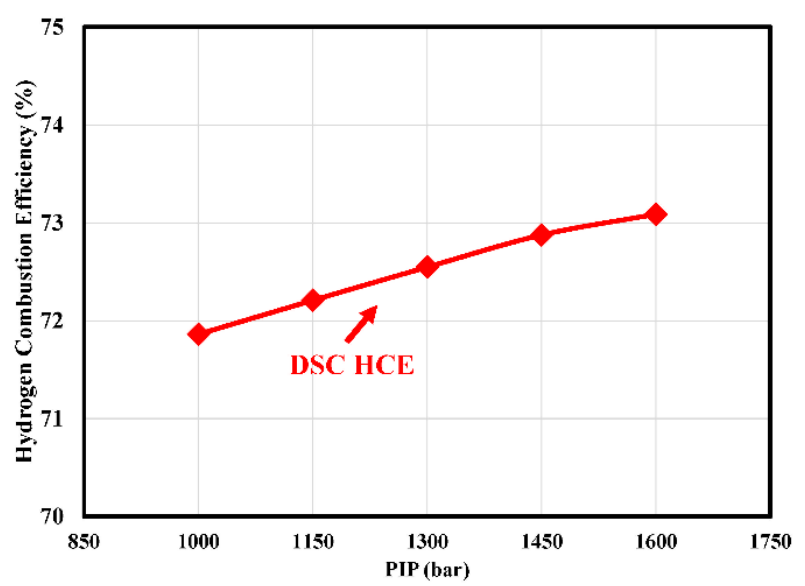

(d) $\mathrm{HCE}$

Figure 14. Effects of post-injection pressure on (a) burning timings, (b) HRR, (c) In-cylinder mean temperature, and (d) HCE.

Figure 15 shows the effects of post-injection pressure on NOx, PM, CO, and UHC emissions. According to Figure 15(a), by increasing PIP, NOx emissions due to enhanced mixture oxidation and higher HRRPP of the second combustion 
event increased under PDC and DSC conditions. However, as can be seen from Figure 15(a), at 1600 bar PIP under PDC engine operating condition, NOx noticeably decreased. This can be related to inefficient mixture formation of the second fuel injection pulse which is caused by shorter spray tip penetration and lower oxygen concentration near the nozzle area. Also, it can be seen from Figure 15(a) under PDC condition, by increasing PIP up to 1450 bar, PM emission diminished that can be due to rapid mixture oxidation, which prevented more PAH formation. However, at 1600 bar PIP, more PM emission was observed in the exhaust gases. This can be attributed to deteriorated mixture formation as a result of lower oxygen concentration and, consequently, poor flame propagation, which caused more diesel misfires.

Figure 15(b) shows the effects of post-injection pressure on CO and UHC emissions under PDC and DSC conditions. As can be seen from Figure 15(b), by increasing PIP up to 1450 bar both CO and UHC emissions decreased. This can be attributed to the fact that higher injection pressure can decrease spray tip penetration, and consequently, less portion of post fuel injection can reach the cylinder wall and crevices. Also, increasing PIP led to higher HRRPP of the second combustion event and improved mixture oxidation. Thus, carbon species oxidation enhanced, and less CO was observed in the exhaust gases. However, at 1600 bar PIP under PDC operating conditions, CO and UHC emissions simultaneously increased. This can be due to more diesel misfires caused by lower oxygen concentration and shorter spray tip penetration, which led to poor flame propagation.

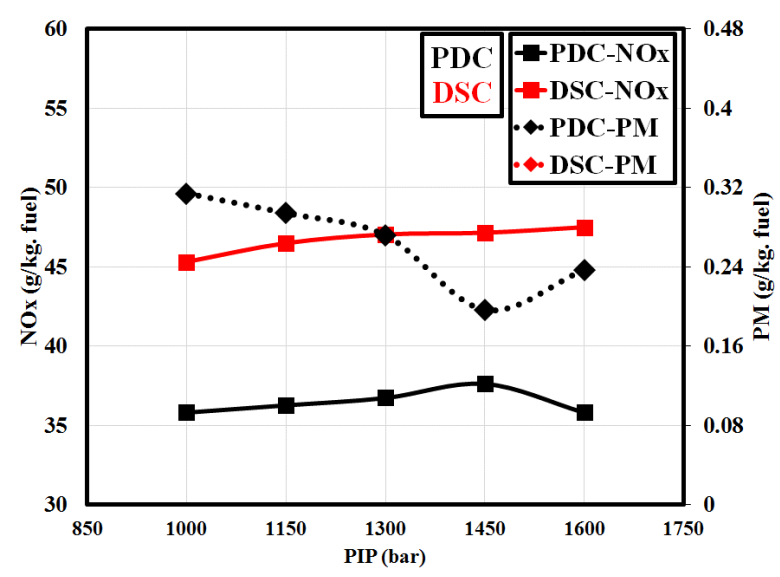

(a) NOx and PM vs. PIP

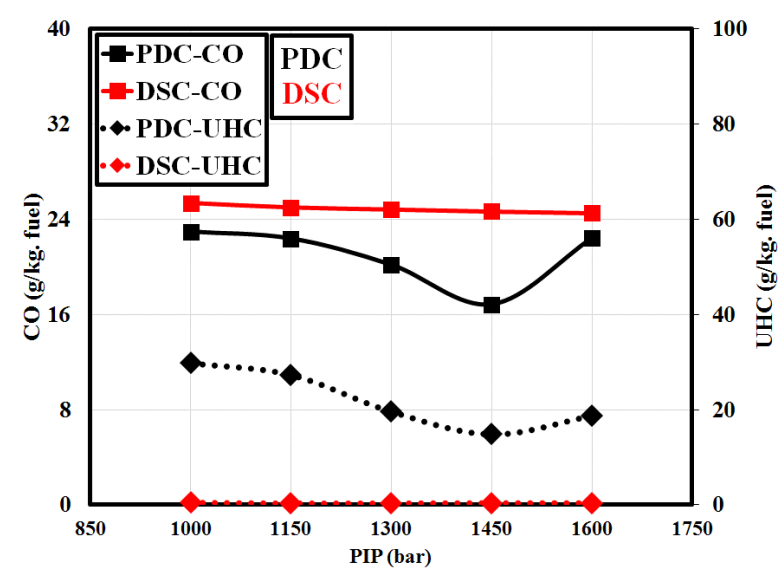

(b) $\mathrm{CO}$ and UHC vs. PIP

Figure 15. Effects of post-injection pressure on (a) NOx-PM and (b) CO-UHC

Figure 16 illustrates the influence of post-injection pressure on indicated thermal efficiency under PDC and DSC operating cases. By increasing PIP from 1000 to 1450 bar, ITE noticeably increased. This can be due to the improvement of the second air-fuel mixture formation that led to higher in-cylinder temperature during the second combustion event; thus, expansion stroke utilisation was enhanced. However, at 1600 bar ITE decreased under both PDC and DSC cases which can be related to the reduction of spray tip penetration inside the combustion chamber. Therefore, the second airfuel mixture formation weakened and resulted in more energy loss and unburnt mixture inside the exhaust gases.

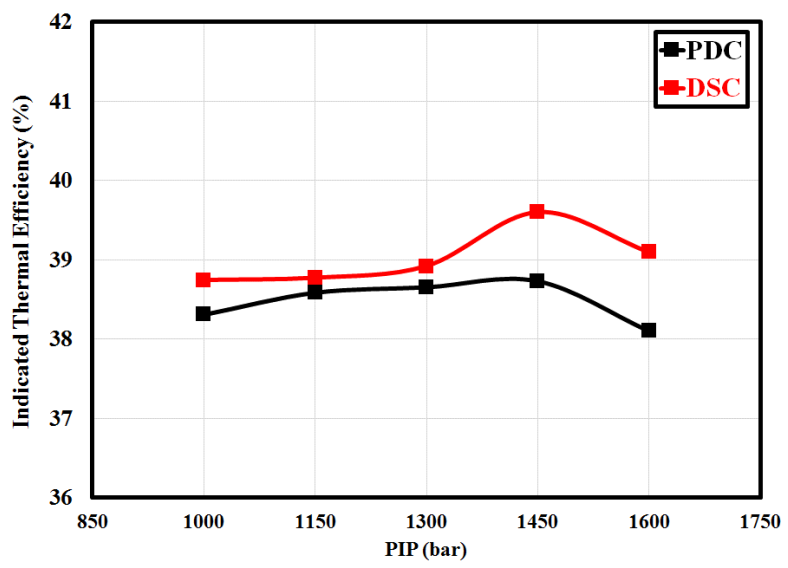

Figure 16. ITE vs PIP under PDC and DSC operating modes.

\section{CONCLUSION}

The main purpose of this numerical research was to investigate the effects of syngas addition and post-injection characteristics on the combustion, engine-out emissions, and performance in a heavy-duty DI diesel engine. The obtained results revealed that:

i. By replacing $40 \%$ of diesel fuel with syngas, the ID period shortened, and HRRPP increased. Also, the temperature rise rate increased and resulted in a higher combustion temperature compared to PDC conditions. 
Regarding emissions formation, PM and UHC significantly decreased near zero. However, NOx and CO emissions simultaneously increased. Moreover, ITE noticeably improved compared to PDC operating case.

ii. Retarding post-injection timing led to prolonged combustion duration. HRRPP and TPP for the second combustion event decreased and consequently, HCE and ITE deteriorated. Regarding emissions formation, PM and $\mathrm{CO}$ emissions noticeably increased compared to baseline PDC conditions. However, the NOx level decreased.

iii. By advancing main-injection timing, the ID period is prolonged and more portion of the air-fuel mixture burnt in premixed combustion. Thus, the flame temperature increased and resulted in improved flame propagation inside the combustion chamber. Furthermore, carbon-based emissions such as PM, CO, and UHC significantly decreased under all engine operating conditions. However, NOx emissions increased under PDC and DSC conditions. Also, regarding engine performance, at MIT of $18 \mathrm{CA}$ BTDC, ITE enhanced by nearly $1.9 \%$ and $3.9 \%$ under PDC and DSC operating conditions compared to the baseline cases, respectively.

iv. Increasing post-injection quantity up to $15 \%$ led to a simultaneous decrement of NOx emissions and ITE under PDC and DSC conditions. Moreover, CO, PM, and UHC emissions increased under PDC and DSC conditions. Also, at 20 and 25\% PIQ, TPP for the second combustion event increased, and as a result, PM oxidation improved under all engine operating conditions.

v. By increasing post-injection pressure under PDC and DSC conditions, HRRPP and TPP of the late combustion event increased and led to less unburnt $\mathrm{H}_{2}$ to be observed in the exhaust gases and increment of ITE. In the case of emissions formation, PM, CO, and UHC decreased at PDC and DSC conditions. However, at 1600 bar PIP under PDC engine operating conditions, HRRPP and TPP of the second combustion event decreased, and also, $\mathrm{CO}$ and $\mathrm{PM}$ emissions increased compared with baseline conditions.

\section{ACKNOWLEDGEMENT}

The authors gratefully acknowledge the Ayatollah Boroujerdi University to provide financial support (grant number 15664-215209) for this research.

\section{REFERENCES}

[1] H.J. Kim, S.H. Park, and C.S. Lee, "Impact of fuel spray angles and injection timing on the combustion and emission characteristics of a high-speed diesel engine," Energy, vol. 107, pp. 572-579, 2016, doi: doi.org/10.1016/j.energy.2016.04.035.

[2] E. Ansari, M. Shahbakhti, and J. Naber, "Optimisation of performance and operational cost for a dual mode diesel-natural gas RCCI and diesel combustion engine," Appl. Energy, vol. 231, pp. 549-561, 2018, doi: doi.org/10.1016/j.apenergy.2018.09.040.

[3] R. Mobasheri, M. Seddiq, and Z. Peng, "Separate and combined effects of hydrogen and nitrogen additions on diesel engine combustion,” Int. J. Hydrog. Energy, vol. 43, no. 3, pp. 1875-1893, 2018, doi: doi.org/10.1016/j.ijhydene.2017.11.070.

[4] C.B. How, N.M. Taib, and M.R.A. Mansor, "Performance and exhaust gas emission of biodiesel fuel with palm oil based additive in direct injection compression ignition engine," Int. J. Automot. Mech. Eng., vol. 16, no. 1, pp. 6173-6187, 2019, doi: 10.15282/ijame.16.1.2019.7.04.

[5] M.A. Mossa et al., "Effects of hot exhaust gas recirculation (EGR) on the emission and performance of a single-cylinder diesel engine," Int. J. Automot. Mech. Eng., vol. 16, no. 2, pp. 6660-6674, 2019, doi: 10.15282/ijame.16.2.2019.14.0501.

[6] P.T. Selvan and G.S. Goteti, "Performance, emission and combustion characteristics of VCR CRDI diesel engine fuelled with n-butanol blends," Int. J. Automot. Mech. Eng., vol. 16, no. 3, pp. 6825-6843, 2019, doi: 10.15282/ijame.16.3.2019.01.0513.

[7] A.O. Emiroğlu, "Effect of fuel injection pressure on the characteristics of single cylinder diesel engine powered by butanoldiesel blend," Fuel, vol. 256, pp. 115928, 2019, doi: 10.1016/j.fuel.2019.115928.

[8] W. Liu and C. Song, "Effect of post injection strategy on regulated exhaust emissions and particulate matter in a HSDI diesel engine," Fuel, vol. 185, pp. 1-9, 2016, doi: 10.1016/j.fuel.2016.07.057.

[9] H. Li et al., "Assessment of the impact of post-injection on exhaust pollutants emitted from a diesel engine fueled with biodiesel," Renew. Energy, vol. 114, pp. 924-933, 2017, doi: 10.1016/j.renene.2017.07.105.

[10] T. Wu et al., "Effect of diesel late-injection on combustion and emissions characteristics of diesel/methanol dual fuel engine," Fuel, vol. 233, pp. 317-327, 2018, doi: 10.1016/j.fuel.2018.06.063.

[11] Y. Wu et al., "Effect of post-injection on combustion and exhaust emissions in DI diesel engine," Fuel, vol. 258, pp. 116131, 2019, doi: 10.1016/j.fuel.2019.116131.

[12] M. Pan et al., "Experimental and numerical study on flow, combustion and emission characteristics of CI engine fueled with n-butanol/diesel blends under post-injection strategy," Fuel, vol. 292, pp. 120267, 2021, doi: 10.1016/j.fuel.2021.120267.

[13] R.D. Reitz and G. Duraisamy, "Review of high efficiency and clean reactivity controlled compression ignition (RCCI) combustion in internal combustion engines," Prog. Energy Combust. Sci., vol. 46, pp. 12-71, 2015, doi: 10.1016/j.pecs.2014.05.003.

[14] A. Yousefi, H. Guo, and M. Birouk, "Effect of diesel injection timing on the combustion of natural gas/diesel dual-fuel engine at low-high load and low-high speed conditions," Fuel, vol. 235, pp. 838-846, 2019, doi: 10.1016/j.fuel.2018.08.064.

[15] J.J. Hernández, M. Lapuerta, and J. Barba, "Separate effect of H2, CH4 and CO on diesel engine performance and emissions under partial diesel fuel replacement," Fuel, vol. 165, pp. 173-184, 2016, doi: 10.1016/j.fuel.2015.10.054.

[16] M. Talibi et al., "Comparative analysis of H2-diesel co-combustion in a single cylinder engine and a chassis dynamometer vehicle," Int. J. Hydrog. Energy, vol. 44, no. 2, pp. 1239-1252, 2019, doi: 10.1016/j.ijhydene.2018.11.092.

[17] M. Ebrahimi and S.A. Jazayeri, "Effect of hydrogen addition on RCCI combustion of a heavy duty diesel engine fueled with landfill gas and diesel oil," Int. J. Hydrog. Energy, vol. 44, no. 14, pp. 7607-7615, 2019, doi: 10.1016/j.ijhydene.2019.02.010.

[18] J. Zareei et al., "The effect of hydrogen addition to compressed natural gas on performance and emissions of a DI diesel engine by a numerical study," Int. J. Hydrog. Energy, vol. 45, no. 58, pp. 34241-34253, 2020, doi: 10.1016/j.ijhydene.2020.09.027. 
[19] F.D.F. Chuahy and S.L. Kokjohn, "Effects of reformed fuel composition in "single" fuel reactivity controlled compression ignition combustion," Appl. Energy, vol. 208, pp. 1-11, 2017, doi: 10.1016/j.apenergy.2017.10.057.

[20] L. Tartakovsky, and M. Sheintuch, "Fuel reforming in internal combustion engines," Prog. Energy Combust. Sci., vol. 67, pp. 88-114, 2018, doi: 10.1016/j.pecs.2018.02.003.

[21] Z. Xu et al., "Computational optimisation of fuel supply, syngas composition, and intake conditions for a syngas/diesel RCCI engine," Fuel, vol. 234, pp. 120-134, 2018, doi: 10.1016/J.FUEL.2018.07.003.

[22] M. Krishnamoorthi, S. Sreedhara, and P.P. Duvvuri, "Experimental, numerical and exergy analyses of a dual fuel combustion engine fuelled with syngas and biodiesel/diesel blends," Appl. Energy, vol. 263, pp. 114643, 2020, doi: 10.1016/j.apenergy.2020.114643.

[23] K.J. Richards, P.K. Senecal, and E. Pomraning, CONVERGE v2. 3 Manual. Convergent Science, Inc., Madison, WI., 2016.

[24] P.K. Senecal et al., "Multi-dimensional modeling of direct-injection diesel spray liquid length and flame lift-off length using CFD and parallel detailed chemistry," SAE transact., pp. 1331-1351, 2003, doi: 10.4271/2003-01-1043.

[25] H. Wang et al., "Development of an n-heptane/toluene/polyaromatic hydrocarbon mechanism and its application for combustion and soot prediction," Int. J. Engine Res., vol. 14, no. 5, p. 434-451, 2013, doi: 10.1177/1468087412471056.

[26] A. Babajimopoulos et al., "A fully coupled computational fluid dynamics and multi-zone model with detailed chemical kinetics for the simulation of premixed charge compression ignition engines," Int. J. Engine Res., vol. 6, no. 5, p. 497-512, 2005, doi: $10.1243 / 146808705 X 30503$.

[27] R.D. Reitz and F.V. Bracco, "Mechanisms of breakup of round liquid jets," The Encyclopedia of Fluid Mechanics, vol. 3, pp. 223-249, 1986,

[28] D.P. Schmidt, and C.J. Rutland, “A new droplet collision algorithm,” J. Comput. Phys., vol. 164, no. 1, pp. 62-80, 2000, doi: $10.1006 /$ jcph.2000.6568.

[29] J.D. Naber and R.D. Reitz, "Modeling engine spray/wall impingement," SAE transact., p. 118-140, 1988, doi: 10.4271/880107.

[30] A.A. Amsden, P.J. O'Rourke, and T.D. Butler, "KIVA- II: A computer program for chemically reactive flows with sprays," Los Alamos National Laboratory Technical Report, LA-11560-MS, 1989, doi: 10.2172/6228444.

[31] V. Yakhot et al., "Development of turbulence models for shear flows by a double expansion technique," Phys. Fluids A: Fluid Dyn., vol. 4, no. 7, pp. 1510-1520, 1992, doi: 10.1063/1.858424.

[32] F.D. Chuahy and S.L. Kokjohn, "High efficiency dual-fuel combustion through thermochemical recovery and diesel reforming," Appl. Energy, vol. 195, pp. 503-522, 2017,doi: 10.1016/j.apenergy.2017.03.078.

[33] M.E. Soberanis and A. Fernandez, "A review on the technical adaptations for internal combustion engines to operate with gas/hydrogen mixtures," Int. J. Hydrog. Energy, vol. 35, no. 21, pp. 12134-12140, 2010, doi: 1016/j.ijhydene.2009.09.070. 